OPEN ACCESS

Edited by:

Xuguang (Sean) Li, Health Canada, Canada

Reviewed by:

Michael Johnston,

Health Canada, Canada Vishal Khatri,

University of Illinois at Rockford,

United States

*Correspondence: Xiangrui $\mathrm{LI}$

lixiangrui@njau.edu.cn

Specialty section:

This article was submitted to Vaccines and Molecular Therapeutics,

a section of the journal

Frontiers in Immunology

Received: 17 June 2021 Accepted: 06 August 2021 Published: 27 August 2021

Citation:

Yu Z, Cao W, Gao X, Aleem MT, Liu J, Luo J, Yan R, Xu L, Song $X$ and Li X (2021) With Chitosan and PLGA as the

Delivery Vehicle, Toxoplasma gondii Oxidoreductase-Based DNA Vaccines Decrease Parasite Burdens in Mice. Front. Immunol. 12:726615. doi: 10.3389/fimmu.2021.726615

\section{With Chitosan and PLGA as the Delivery Vehicle, Toxoplasma gondii Oxidoreductase-Based DNA Vaccines Decrease Parasite Burdens in Mice}

\author{
Zhengqing $\mathrm{Yu}^{1}$, Wandi Cao ${ }^{1}$, Xuchen Gao ${ }^{1}$, Muhammad Tahir Aleem ${ }^{1}$, Junlong Liu ${ }^{2}$, \\ Jianxun Luo ${ }^{2}$, Ruofeng Yan ${ }^{1}$, Lixin Xu ${ }^{1}$, Xiaokai Song ${ }^{1}$ and Xiangrui $\mathrm{Li}^{1{ }^{1 *}}$ \footnotetext{
Nanjing Agricultural University, Nanjing, China, ${ }^{2}$ State Key Laboratory of Veterinary Etiological Biology, Key Laboratory of Veterinary Parasitology of Gansu Province, Lanzhou Veterinary Research Institute, Chinese Academy of Agricultural Sciences, Lanzhou, China
} \\ ${ }^{1}$ Ministry of Education (MOE) Joint International Research Laboratory of Animal Health and Food Safety, College of Veterinary Medicine,
}

Toxoplasma gondii (T. gondii) is an intracellular parasitic protozoan that can cause serious public health problems. However, there is no effectively preventive or therapeutic strategy available for human and animals. In the present study, we developed a DNA vaccine encoding $T$. gondii oxidoreductase from short-chain dehydrogenase/reductase family (TgSDRO-pVAX1) and then entrapped in chitosan and poly lactic-co-glycolic acid (PLGA) to improve the efficacy. When encapsulated in chitosan (TgSDRO-pVAX1/CS nanospheres) and PLGA (TgSDRO-pVAX1/PLGA nanospheres), adequate plasmids were loaded and released stably. Before animal immunizations, the DNA vaccine was transfected into HEK 293-T cells and examined by western blotting and laser confocal microscopy. Th1/Th2 cellular and humoral immunity was induced in immunized mice, accompanied by modulated secretion of antibodies and cytokines, promoted the maturation and $\mathrm{MHC}$ expression of dendritic cells, and enhanced the percentages of $\mathrm{CD}^{+}$and $\mathrm{CD}^{+}{ }^{+} \mathrm{T}$ lymphocytes. Immunization with TgSDRO-pVAX1/CS and TgSDROpVAX1/PLGA nanospheres conferred significant immunity with lower parasite burden in the mice model of acute toxoplasmosis. Furthermore, our results also lent credit to the idea that TgSDRO-pVAX1/CS and TgSDRO-pVAX1/PLGA nanospheres are substitutes for each other. In general, the current study proposed that TgSDRO-pVAX1 with chitosan or PLGA as the delivery vehicle is a promising vaccine candidate against acute toxoplasmosis.

Keywords: Toxoplasma gondii, oxidoreductase, chitosan, PLGA, immune protection, mouse 


\section{INTRODUCTION}

As an obligate intracellular parasite, Toxoplasma gondii (T. gondii) can infect almost all warm-blooded vertebrates and are widespread in humans $(1,2)$. Most $T$. gondii infections are asymptomatic, but a serious threat can be posed to immunocompromised patients and those with congenital toxoplasmosis (3). Based on the published paper, toxoplasmosis may occur by ingestion of contaminated meat, water, or even vegetables (4-6). Such high disease burden makes T. gondii one of the most important food-borne microorganisms and emphasizes the necessity to intervene (7). Invalid to the bradyzoites of $T$. gondii, pyrimethamine (PYR) and sulfadiazine (SDZ) have been permitted for the treatment of tachyzoites (8), implying that chronic toxoplasmosis caused by bradyzoites cannot be eradicated (9). Thus, development of effective protective and therapeutic strategies needs to be improved (10). Currently, effective treatments for toxoplasmosis are still unavailable, and the prevention strategies are considered effectively (11). Commercially available Ovilis Toxovax ${ }^{\circledR}$ (Intervet Inc., Angers, France), a live attenuated vaccine, prepared by the T. gondii S48 strain has been licensed in the prevention of toxoplasmosis in goats and sheep (12). However, the Food Standards Agency questioned its protective immunity in tissue cyst formation (13). In general, it is an urgent and valued requirement to develop an effective vaccine against T. gondii infection.

A safe and effective vaccine against $T$. gondii may be the promising way to protect against toxoplasmosis (14). Currently, studies on vaccines against $T$. gondii have mainly focused on finding promising vaccine targets and demonstrating its protections in immunity (15). Eliciting strong cellular and humoral immunity against $T$. gondii, an effective vaccine target should be highly immunogenic and improbable to induce autoimmune and allergic reactions (15). Numerous vaccine targets have been evaluated in different types of vaccines against $T$. gondii, and these targets mainly include dense granule proteins (16), surface proteins (17), rhoptry proteins (18), microneme proteins (19), etc. However, these vaccine targets cannot fully protect against the virulent challenge, and a suitable vaccine is still unavailable (20-22). The short-chain dehydrogenases/reductases family (SDR family) is a large family of enzymes in eukaryotes and a potential vaccine target (23), which is involved in the synthesis of molecules, including lipids, vitamins, drugs, and carbohydrates (24). A 368-amino acid protein encoded as "oxidoreductase" from the T. gondii SDR family in the Uniprot database (https://www.uniprot.org/) aroused our particular attention. The NADPH-dependent oxidoreductase is characterized by 3-oxoacyl-ACP reductase (NADPH) activity $(25,26)$ and plays essential roles in fatty acid biosynthesis, and is a critical enzyme in the synthesis of poly( $\beta$-Hydroxybutyric acid), $\beta$-ketothiolase, and polyhydroxyalkanoate (PHA) synthase (27). It has been demonstrated that the apical complex exerts great functions on the invasion of apicomplexan parasites (28). Harboring metabolic processes that are important in fatty acid biosynthesis, the apical complex is indispensable for parasite viability $(29,30)$. Thus, construction of specifically targeting the activity of oxidoreductase vaccines looks rational in the prevention of $T$. gondii infection.
With the emergence of new antigens, adjuvants, and therapeutics, vaccines against toxoplasmosis evolved noticeably. In recent years, many studies have evaluated the immune protection triggered by DNA vaccines encoding a single or multicomponent antigen against toxoplasmosis in a mice model $(17,18,31)$. As a DNA vaccine vector, pVAX1 is approved by the Food and Drug Administration (FDA). Furthermore, gene expression levels tend to be a key factor to evaluate the protective efficacy of a genetic vaccine. Thus, a delivery system for DNA vaccines should be applied with the aim to enhance the expression of transferred antigens to evoke adequate immune protection (32). To decrease the dose of plasmids and protect the plasmids from degradation, numerous studies have been focused on an efficient delivery system (33). Nowadays, many synthetic delivery systems have been reported for their improvement in immune response (34). Widely used in polymer materials for vaccine and drug delivery system, poly lactic-coglycolic acid (PLGA) approved by FDA is characterized by easy biodegradability, nontoxicity, and good biocompatibility (35). Also approved for wound dressings by FDA (36), chitosan has been illustrated to be safe in parts of dietary applications (37). Chitosan is also suitable for biomedical applications largely due to being biocompatible, biodegradable, and relatively safe (38-40).

In the present study, we made a new attempt in combining T. gondii oxidoreductase from SDR family (TgSDRO) with PLGA and chitosan nanospheres to develop a DNA vaccine against $T$. gondii infection in mice. In addition, the immune protections of two types of nanospheres were also evaluated. In this context, the aim of this study was to develop a DNA vaccine against acute toxoplasmosis delivered by PLGA or chitosan.

\section{MATERIALS AND METHODS}

\section{Ethics Statements}

All animal experiments were approved by the Animal Ethics committee of responsible authority from the College of Veterinary Medicine, Nanjing Agricultural University, China (permission: NJAU. No20210315014).

\section{Animals, Cell Lines, and Parasites}

Specific pathogen-free (SPF) BALB/c mice (18-22 g, female) and Sprague-Dawley (SD) rats (200-220 g, female) were purchased from Model Animal Research Center of Nanjing University, Nanjing University, China. All animals were strictly housed in a specific pathogen-free environment following the requirements of the Animal Ethics Procedures and Guidelines of the People's Republic of China.

Human embryonic kidney 293-T (HEK 293-T) cells were obtained from the Institute of Cell Biology, Chinese Academy Sciences, Shanghai, China, and preserved in our laboratory. HEK 293-T cells were cultured in Dulbecco's Modified Eagle's Medium (DMEM, Gibco, Carlsbad, CA, USA) containing 10\% fetal bovine serum (FBS, Gibco, Carlsbad, CA, USA) and 1\% double antibiotics (Carlsbad, Gibco, CA, USA) at $37^{\circ} \mathrm{C}$ in a $5 \%$ $\mathrm{CO}_{2}$ atmosphere. 
Tachyzoites of the violent $T$. gondii $\mathrm{RH}$ strain (type I) were maintained in the Ministry of Education (MOE) Joint International Research Laboratory of Animal Health and Food Safety, College of Veterinary Medicine, Nanjing Agricultural University, Nanjing, China. Tachyzoites used in this study were replicated in BALB/c mice according to a previous study (41).

\section{Construction of the Eukaryotic Expression Plasmid}

Strictly following the instructions, the total RNA of $10^{6}$ tachyzoites of T. gondii was isolated by using the Total RNA Extraction kit (OMEGA Bio-tek, Norcross, GA, USA). Reverse transcription PCR (RT-PCR) was immediately conducted to synthesize the cDNA by a reverse transcription kit (Takara Biotechnology, Dalian, China). Primers amplifying the complete open reading frame (ORF) of TgSDRO were designed based on the conserved domain sequences (CDS) of the TgSDRO gene (GenBank: AAYL02000041). Along with the restriction endonuclease sites (EcoRI and XhoI) and a Kozak translation initiation sequence, the forward and reverse primers, 5'CCG GAATTC GCCACC ATGGATATTCAAGCGGTTGGGA-3' and 5'-CCGCTCGAGTCAGGTGGAATGCGGGGG-3', were synthesized by the company (Tsingke Biological Technology, Nanjing, China). For PCR amplification, 1.25 U Ex Taq DNA polymerase (Takara Biotechnology, Dalian, China), $5 \mu \mathrm{l} 10 \times$ Ex Taq buffer, $4 \mu \mathrm{l}$ dNTP mixtures $\left(\mathrm{Mg}^{2+}\right.$ plus), $20 \mathrm{pmol}$ of each primer, 2 ng cDNA template, and $\mathrm{dd}_{2} \mathrm{O}$ to make a final volume of $50 \mu$ l were involved in each reaction. The amplification was determined by an amplifier (Thermo Scientific, Waltham, MA, USA) using the following program: preheating $\left(5 \mathrm{~min}\right.$ at $\left.95^{\circ} \mathrm{C}\right)$, amplification for 35 cycles of $30 \mathrm{~s}$ at $95^{\circ} \mathrm{C}, 30 \mathrm{~s}$ at $64^{\circ} \mathrm{C}$ and $70 \mathrm{~s}$ at $72^{\circ} \mathrm{C}$, and the final extension $\left(5 \mathrm{~min}\right.$ at $72^{\circ} \mathrm{C}$ ). Then, $10 \mu \mathrm{l} \mathrm{PCR} \mathrm{amplicons} \mathrm{were}$ analyzed in a $1.0 \%$ agarose gel containing $0.01 \%$ ethidium bromide. The single band with expected base pairs was then purified by using a Gel Eradication Kit (OMEGA Bio-tek, Norcross, GA, USA). After being digested with EcoRI and XhoI restriction endonuclease (Takara Biotechnology, Dalian, China), the obtained PCR amplicons were inserted into the linear pVAX1 vector (Invitrogen Biotechnology, Shanghai, China) by using T4 DNA ligase (Takara Biotechnology, Dalian, China). The recombinant plasmids were identified by double restriction enzyme digestion and then sequenced by the ABI PRISM ${ }^{\mathrm{TM}} 3730$ XL DNA Analyzer (Applied Biosystems, Waltham, MA, USA). The positive plasmid was transferred to Escherichia coli (E. coli) $\mathrm{DH} 5 \alpha$ (Invitrogen Biotechnology, Shanghai, China).

To obtain a large quantity of recombinant plasmid, E. coli $\mathrm{DH} 5 \alpha$ carrying the recombinant plasmid was amplified in a Luria Bertani (LB) medium containing $100 \mu \mathrm{g} / \mathrm{ml}$ kanamycin monosulfate until the OD600 reached $0.6\left(37^{\circ} \mathrm{C}\right.$ and shaking at $180 \mathrm{rpm})$. Endo-free DNA plasmid was extracted by a commercially available kit (Vazyme, Nanjing, China) in a large quantity, and then the level of endotoxin was determined by a ToxinSensor $^{\mathrm{TM}}$ Chromogenic LAL Endotoxin Assay Kit (GeneScript, Piscataway, NJ, USA). After concentration determination by a nanodrop microvolume spectrophotometer (Thermo Scientific, Waltham, MA, USA), the recombinant plasmids were stored at $-20^{\circ} \mathrm{C}$ until use.

\section{Recombinant Plasmids Transfection In Vitro}

The liposomal transfection method was used for the delivery of plasmids in HEK 293-T cells $\left(1 \times 10^{6}\right.$ cells) cultured in a 6-well plate (Costar, Cambridge, MA, USA) with $70-90 \%$ confluence, then a Lipofectmine $^{\mathrm{TM}} 3000$ reagent (Invitrogen Biotechnology, Shanghai, China) was used as the transfection reagent for making the plasmid-lipid complex according to the instructions. The transfected cells were incubated for 15 min before replacing the medium with $2 \mathrm{ml}$ of fresh medium. Three days later, the cultured medium was removed, and the cells were washed with phosphate buffered saline (PBS) for three times. Then cells were scraped into $250 \mu \mathrm{l}$ RIPA lysis buffer (Beyotime, Shanghai, China) containing $10 \mu \mathrm{l}$ protease and phosphatase inhibitor (Beyotime, Shanghai, China). Tip sonication (Scientz Biotechnology, Ningbo, China) was conducted in a continuous mode for $2 \mathrm{~s}$ at $2 \mathrm{~s}$ ( $5 \mathrm{~min}$ in total) under the output power of $20 \mathrm{~W}$, and then the cell lysates were stored at $-20^{\circ} \mathrm{C}$ until use.

To obtain the cell culture medium containing recombinant protein, the culture medium was first renewed after a 3-day cultivation, and then the transfected cells were scraped into the medium; then the tip sonication was conducted in the same continuous mode mentioned above under sterile condition. The cell culture medium was collected and stored at $-20^{\circ} \mathrm{C}$ after centrifugation at $12,000 \mathrm{rpm}$ for $5 \mathrm{~min}$ at $4^{\circ} \mathrm{C}$.

\section{Immunofluorescence Staining}

To obtain the serum against T. gondii, two SD rats were challenged with $10^{3}$ tachyzoites of T. gondii RH strain intraperitoneally. One month later, the serum containing the antibodies against $T$. gondii was harvested. All sera were kept at $-20^{\circ} \mathrm{C}$ until use.

The transfected HEK 293-T cells were prepared following the method described in the section Recombinant Plasmids Transfection in Vitro. With 3-day stationary cultivation after transfection in the medium, cells were washed with PBS for three times and fixed with $1 \mathrm{ml} 4 \%$ paraformaldehyde for $12 \mathrm{~h}$ at $4^{\circ} \mathrm{C}$. Permeabilized with tris buffered saline (TBS) containing $0.1 \%$ Triton X-100 (TBSx) for $3 \mathrm{~min}$ on a rotary shaker at $50 \mathrm{rpm}$, cells were subsequently incubated with TBSx containing 5\% BSA and $1 \%$ serum obtained from $T$. gondii-infected rats for $1 \mathrm{~h}$ on a rotary shaker at $37^{\circ} \mathrm{C}$. Diluted 1:500 in TBSx containing 5\% BSA, CY3-conjugated anti-rat IgG (Sigma, Saint Louis, MO, USA) was added to the cells before washing three times in TBSx. After being incubated for $1 \mathrm{~h}$ at $37^{\circ} \mathrm{C}$ on a rotary shaker, $500 \mu \mathrm{l}$ of $4^{\prime}, 6-$ diamidino-2-phenylindole (DAPI) staining solution (Beyotime, Shanghai, China) was added in each well. After being stained for $5 \mathrm{~min}$ at $37^{\circ} \mathrm{C}$ on a rotary shaker, DAPI staining solution was removed, and the cells were washed three times in TBSx. Cover lips were mounted with $300 \mu \mathrm{l}$ anti-fade mounting medium (Beyotime, Shanghai, China) and the image was taken by a Nikon A1 plus laser scanning confocal microscopy (Nikon Corporation, Tokyo Metropolis, Japan).

\section{Western Blot Analysis}

HEK 293-T cell lysates were added with $10 \times$ loading buffer and heated at $95-100^{\circ} \mathrm{C}$ for $5 \mathrm{~min}$. Separated by $12 \%$ SDS-PAGE, 
HEK 293-T cell lysates were electro-transferred onto polyvinylidene difluoride (PVDF) membranes (Millipore, Billerica, MA, USA). The membranes were then incubated with $5 \%(w / v)$ BSA in TBS containing $0.5 \%(v / v)$ tween 20 (TBST) for $2 \mathrm{~h}$ at $37^{\circ} \mathrm{C}$ on a rotary shaker with $50 \mathrm{rpm}$. After three times washing in TBST, the membranes were subsequently incubated with TBST containing $1 \%(v / v)$ rat serum at $4^{\circ} \mathrm{C}$ overnight with constant shaking. Washed with TBST in triplicate, the membranes were incubated with HRPconjugated anti-rat IgG (1:5,000, eBioscience, San Diego, CA, USA) dissolved in TBST for $1 \mathrm{~h}$ at $37^{\circ} \mathrm{C}$ on a rotary shaker. After three times washing in TBST, the membranes were incubated with newly prepared 3,3'-diaminobenzidine (DAB, Sigma-Aldrich, Saint Louis, MO, USA) for $10 \mathrm{~min}$.

\section{Synthesis of Vaccines Delivered by PLGA}

According to a previous study (42), the double emulsion solvent evaporation technique $(w / o / w)$ was used for the synthesis of PLGA nanospheres loaded with TgSDRO-pVAX1 plasmid (TgSDRO-pVAX1/PLGA nanospheres) with minor modifications. Briefly, to construct the organic phase, $5 \mathrm{mg}$ of PLGA (MW: 40,000-75,000 Da, LA/GA: 65/35, Sigma, Saint Louis, MO, USA) was dissolved in $1 \mathrm{ml}$ dichloromethane (DCM, Sigma, Saint Louis, MO, USA). Subsequently, $2 \mathrm{mg}$ (the concentration was $1 \mathrm{mg} / \mathrm{ml}$ ) purified plasmids were dropwise dissolved in $2 \mathrm{ml}$ of $6 \%(w / v)$ polyvinyl alcohol (PVA, MW: 31,000-75,000 Da, Sigma, Saint Louis, MO, USA) with a plastic pipette tip at room temperature to construct the aqueous phase. For the 6\% PVA solution, PVA was dissolved in double-distilled water and passed through a $0.22-\mu \mathrm{m}$ filtering membrane (Millipore, Billerica, MA, USA). After the aqueous phase was thoroughly mixed on a vortex mixer for $2 \mathrm{~min}$, the organic phase was dropped into the aqueous phase on a magnetic stirrer (400 $\mathrm{rpm}$ ) using a plastic pipette tip. To form the $w / o / w$ emulsions, tip sonication (Scientz Biotechnology, Ningbo, China) was then conducted in a continuous mode for $5 \mathrm{~s}$ at $5 \mathrm{~s}$ (4 min in total) under the output power of $50 \mathrm{~W}$ in an ice bath. To evaporate $\mathrm{DCM}$, the $w / o / w$ emulsions were stirred at $400 \mathrm{rpm}$ on a magnetic stirrer at $4^{\circ} \mathrm{C}$ overnight. After being centrifuged at $35,000 \mathrm{rpm}$ for $25 \mathrm{~min}$ at $4^{\circ} \mathrm{C}$, the nanospheres were collected and dissolved in double-distilled water, and the supernatant was also obtained to calculate the total amount of plasmids. The obtained nanospheres were passed through a $0.22-\mu \mathrm{m}$ filtering membrane, then frozen at $-80^{\circ} \mathrm{C}$ for at least $2 \mathrm{~h}$. The frozen PLGA nanospheres were quickly transferred to a vacuum freeze dryer (Labconco, Kansas City, MO, USA) until completely freeze-dried. The empty PLGA nanospheres were also prepared by replacing the TgSDRO-pVAX1 plasmid with $\mathrm{PBS}$, and the synthesized PLGA nanospheres were stored at $4^{\circ} \mathrm{C}$ until use.

\section{Synthesis of Vaccines Delivered by Chitosan}

The ionic gelation technique was conducted for the synthesis of chitosan nanospheres loaded with TgSDRO-pVAX1 plasmid (TgSDRO-pVAX1/CS nanospheres) according to a previous study (43). Briefly, $0.1 \mathrm{~g}$ of chitosan (MW 50-190 kDa, Sigma, Saint Louis, MO, USA) was dissolved in $50 \mathrm{ml}$ of $1 \%(v / v)$ aqueous solution of acetic acid. The chitosan solution was then thoroughly mixed on a magnetic stirrer to make chitosan fully dissolved, then the $\mathrm{pH}$ value was adjusted by $2 \mathrm{M} \mathrm{NaOH}$ solution. Sodium tripolyphosphate $(0.02 \mathrm{~g}$; TPP, Aladdin, Shanghai, China) was dissolved in $10 \mathrm{ml}$ double-distilled water and passed through a $0.22-\mu \mathrm{m}$ filtering membrane (Millipore, Billerica, MA, USA). TPP solution (4 ml) was dropwise added to $20 \mathrm{ml}$ of chitosan solution on a magnetic stirrer at a bath temperature of $30^{\circ} \mathrm{C}$, and then $4 \mathrm{mg}$ (the concentration was 1 $\mathrm{mg} / \mathrm{ml}$ ) purified plasmids were dropwise added in. Constant stirring continued at least for $20 \mathrm{~min}$ to make chitosan fully dissolved. Then tip sonication was performed in a continuous mode for $5 \mathrm{~s}$ at $5 \mathrm{~s}$ ( $2 \mathrm{~min}$ in total) under an output power of 50 $\mathrm{W}$ in an ice bath. After being centrifuged at 40,000 rpm for 25 $\min$ at $4^{\circ} \mathrm{C}$, the nanospheres were collected and dissolved in double-distilled water, and the supernatant was also collected to calculate the total amount of plasmids. Before freezing at $-80^{\circ} \mathrm{C}$ for at least $2 \mathrm{~h}$, the nanospheres were passed through a $0.22-\mu \mathrm{m}$ filtering membrane. The frozen chitosan nanospheres were then transferred to a vacuum freeze dryer until completely freezedried. To synthesize empty chitosan nanospheres, PBS, instead of TgSDRO-pVAX1 plasmid, was conducted. The synthesized chitosan nanospheres were stored at $4^{\circ} \mathrm{C}$ until use.

\section{Nanospheres Characterization}

To investigate the encapsulation efficiency (EE) and the loading capacity (LC), the concentration of free plasmids in the supernatant was quantified by a nanodrop microvolume spectrophotometer, and the total amount of free plasmids in the supernatant could be obtained. The EE and LC can be calculated by formula (1) and formula (2), respectively.

$$
\begin{aligned}
& \mathrm{EE}(\%)=\frac{\text { Total plasmid-Free plasmid }}{\text { Total plasmid }} \times 100 \% \\
& \mathrm{LC}(\%)=\frac{\text { Total plasmid-Free plasmid }}{\text { Weight of nanospheres }} \times 100 \%
\end{aligned}
$$

To characterize the features of TgSDRO-pVAX1/PLGA and TgSDRO-pVAX1/CS nanospheres, the nanospheres were sent to Nanjing Agriculture University for scanning electron microscope (SEM) observation by using Hitachi SU8010 (Tokyo, Japan). By using the ImageJ software version 1.8 (NIH Image, Bethesda, MD, USA), the average diameter of nanospheres was determined by measuring five arbitrary nanospheres.

To investigate the integrity of prepared nanospheres, synthesized PLGA and chitosan nanospheres were preserved at $4^{\circ} \mathrm{C}$ for more than 3 months, and the image was taken by SEM as described above. The integrity of two types of nanospheres was then evaluated by analyzing SEM pictures captured at different stages.

\section{Release Characteristics In Vitro}

As referenced to a previous study (44), the release characteristics of TgSDRO-pVAX1/PLGA and TgSDRO-pVAX1/PLGA nanospheres were conducted with minor modifications. Briefly, after being dissolved in $1 \mathrm{ml}$ of $\mathrm{PBS}$ ( $\mathrm{pH} 7.4$ ), $2 \mathrm{mg}$ nanospheres 
were dispersed on a rotary shaker $(180 \mathrm{rpm})$ at $37^{\circ} \mathrm{C}$. The time interval between two sample points was $12 \mathrm{~h}$. To record the total volume of the supernatant and sample the supernatant, the nanospheres solution was centrifuged at 12,000 rpm for $5 \mathrm{~min}$. The nanospheres that settled at the bottom were resuspended, and the tubes were put back. Referenced to the same PBS used for dissolving empty PLGA or chitosan nanospheres (loaded with PBS, instead of TgSDRO-pVAX1 plasmid), the concentrations of plasmid in the supernatant were immediately measured. Then, the cumulative release (CR) was calculated by formula (3). Each group had three replications, and each replication was measured once.

$$
\begin{aligned}
\mathrm{CR}(\%)= & \frac{\text { Total volume of supernatant } \times \text { Plasmid concentration }}{\text { Total weight of nanospheres } \times \text { LC }} \\
& \times 100 \%
\end{aligned}
$$

\section{Quantification of T. gondii in Tissue}

Three BALB/c mice were challenged with 200 tachyzoites of $T$. gondii $\mathrm{RH}$ strain intraperitoneally. Seven days later, infected mice were sacrificed under the supervision of the Animal Ethics Committee, Nanjing Agriculture University, China. Then tissue samples from the intestine, heart, leg muscle, brain, liver, spleen, lung, and kidney were collected and store at $-20^{\circ} \mathrm{C}$ until use.

To detect T. gondii in different tissues, PCR was conducted to amplify the internal transcribed spacer 1 (ITS-1) sequence based on a published paper (45). Briefly, $30 \mathrm{mg}$ of tissue samples was used for genomic DNA extraction according to the instruction (OMEGA Biotek, Norcross, Georgia, USA), and the extracts were stored at $-20^{\circ} \mathrm{C}$ until use. The PCR system was the same as that described in the section Construction of the Eukaryotic Expression Plasmid, and the amplification was determined by using the following program: preheating $\left(5 \mathrm{~min}\right.$ at $95^{\circ} \mathrm{C}$ ), amplification for 40 cycles of $30 \mathrm{~s}$ at $95^{\circ} \mathrm{C}, 30 \mathrm{~s}$ at $55^{\circ} \mathrm{C}$, and $30 \mathrm{~s}$ at $72^{\circ} \mathrm{C}$, and the final extension $(5 \mathrm{~min}$ at $72^{\circ} \mathrm{C}$ ). The positive genomic DNA was obtained from the tachyzoites described in the section Animals, Cell Lines, and Parasites using the same method described above. In each amplification, both positive and negative controls (no-DNA control) were included. Then, $4 \mu \mathrm{l}$ PCR amplicons were visualized in a $1.0 \%$ agarose gel containing $0.01 \%$ ethidium bromide.

To evaluate the parasitic load in tissues, absolute quantitative real-time PCR (qPCR) was conducted to illustrate the 529 bp repeat element in the extracts referenced to a published study (46)' absolute quantitative real-time PCR (qPCR) was conducted to illustrate the $529 \mathrm{bp}$ repeat element in the extracts. The recombinant vector containing the amplified region was also constructed, and the copy numbers of cloned vectors were calculated by using an online tool (http://cels.uri.edu/gsc/cndna. html). For qPCR amplification, $10 \mu \mathrm{l}$ of $2 \times$ ChamQ SYBR qPCR MasterMix (Vazyme, Nanjing, China), 0.4 pmol of each primer, 0.4 $\mu \mathrm{l} 50 \times$ ROX Reference Dye $2,1 \mu \mathrm{l}$ of DNA extracts, and $\mathrm{ddH}_{2} \mathrm{O}$ to make a final volume of $20 \mu \mathrm{l}$ were involved in each reaction. Each reaction was amplified by Applied Biosystems 7500 (Life Technologies, Carlsbad, USA) using the following program: predenaturation at $95^{\circ} \mathrm{C}$ for $30 \mathrm{~s}$, followed by 40 cycles of $95^{\circ} \mathrm{C}$ for $10 \mathrm{~s}$ and $60^{\circ} \mathrm{C}$ for $30 \mathrm{~s}$. A melting curve analysis was performed at the end of the reaction between $60^{\circ} \mathrm{C}$ and $95^{\circ} \mathrm{C}$ with an increment of $0.05^{\circ}$ $\mathrm{C} / \mathrm{s}$. The melting curve of each amplification was ensured with one uniform peak at the expected temperature before further analysis. Before amplification, the OD260/OD280 value of each sample was analyzed by a nanodrop microvolume spectrophotometer. Each tissue had three replications, and each replication was performed once. Moreover, the recombinant vectors with a known copy number were also conducted in triplicate.

\section{Immunization and Challenging Schedules in Mice}

$\mathrm{BALB} / \mathrm{c}$ mice were randomly divided into five groups $(28$ mice/ group), and all mice were immunized intramuscularly in the leg muscles with multipoint at 2 -week intervals. For single immunization, the immunized dosage of each mouse did not exceed $0.2 \mathrm{ml}$. Mice were immunized with an equal volume of PBS that was used as the blank control (Table 1). To investigate the adverse reactions in animals, the living conditions of animals were observed weekly from the first immunization to challenge.

Two weeks after the last immunization, the immune protections were evaluated by a method described previously (47). In short, five mice in every group were challenged with a lethal dose $\left(10^{3}\right.$ tachyzoites) of $T$. gondii RH strain intraperitoneally. The infected mice in each group were sacrificed under supervision 7 days after the challenge, and the specific tissue was collected and stored at $-20^{\circ} \mathrm{C}$ until use.

\section{Antibody and Cytokine Assays}

Serum samples were collected from the eye socket at weeks 0,2 , and 4 before immunization and challenge. All serum samples were kept in $-20^{\circ} \mathrm{C}$ before use. To obtain the soluble tachyzoite antigens (STAg), a previously described procedure was conducted (48).

TABLE 1 | Immunization formulations in mice.

\begin{tabular}{llc}
\hline Group & \multicolumn{1}{c}{ Treatment (each mouse) } & \multicolumn{1}{c}{ Immunization } \\
\hline Blank & Equal volume of PBS & Intramuscular injection in the leg \\
Control & $100 \mu \mathrm{g} \mathrm{pVAX1}$ plasmid & Intraperitoneal infections with $10^{3}$ tachyzoites \\
TgSDRO-pVAX1 & $100 \mu \mathrm{g}$ TgSDRO-pVAX1 plasmid & for each mouse at week 4 \\
TgSDRO-pVAX1/CS & TgSDRO-pVAX1/CS nanospheres containing $100 \mu \mathrm{g}$ & \\
& TgSDRO-pVAX1 plasmid & \\
TgSDRO-pVAX1/PLGA & TgSDRO-pVAX1/PLGA nanospheres containing 100 \\
& Mg TgSDRO-pVAX1 plasmid
\end{tabular}


According to a previous study (49), enzyme linked immunosorbent (ELISA) assays were performed to determine the T. gondii-specific serum antibody levels. Briefly, the 96-well plates (Costar, Cambridge, MA, USA) were coated with $1 \mu \mathrm{g}$ STAg (diluted to $10 \mu \mathrm{g} / \mathrm{ml}$ with carbonate buffer $\mathrm{pH}$ 9.6) for each well overnight at $4^{\circ} \mathrm{C}$. After being washed three times with TBST (TBS containing $0.05 \%$ Tween 20 ), each well was blocked with TBS containing $5 \%$ skimmed milk at $37^{\circ} \mathrm{C}$ for $1 \mathrm{~h}$. Then mouse sera were diluted (1:100 in TBS) and added to each well for $1 \mathrm{~h}$ at $37^{\circ} \mathrm{C}$ after three times washing in TBST. After being subsequently rinsed $5 \mathrm{~min}$ in TBST, each well was incubated with HRP-conjugated anti-mouse IgG, IgG1, or IgG2a (1:5,000, eBioscience, San Diego, USA) at $37^{\circ} \mathrm{C}$ for $1 \mathrm{~h}$ to detect bound antibodies. Finally, 3,3',5,5'-tetramethylbenzidine (TMB, Tiangen, Beijing, China) was used to evaluate the enzymatic activity; the reaction was stopped by adding $100 \mu \mathrm{l}, 2 \mathrm{M}$ newly prepared $\mathrm{H}_{2} \mathrm{SO}_{4}$. The absorbance was measured at $450 \mathrm{~nm}$ with a microplate photometer (Thermo Scientific, Waltham, USA). Each group had five replications, and each replication was measured once.

To assay the cytokine production levels in sera, commercially available ELISA kits (Senbeijia, Nanjing, China) were used strictly following the manufacturer's instructions. Referenced to standard curves based on known amounts of mouse recombinant cytokines, the concentrations of interferongamma (IFN- $\gamma$ ) and interleukin (IL) 4 (IL-4), IL-10, and IL-17 were measured. The analysis was performed based on five replications in each group, and each replication was measured once.

\section{Determination of Lymphocyte Proliferation}

One week after the booster immunization, three mice of each group (without challenge) were sacrificed under supervision to obtain the splenic lymphocytes by using a lymphocyte separation kit (Solarbio, Beijing, China). The splenic lymphocytes were adjusted to $10^{5}$ cells/well in the medium containing recombinant protein obtained in the section Recombinant Plasmids Transfection in Vitro and cultured in a 96-well plate. The plate was incubated for $72 \mathrm{~h}$ at $37^{\circ} \mathrm{C}$. Then $10 \mu \mathrm{l}$ of Cell Counting Kit 8 (CCK-8, Beyotime, Shanghai, China) was added according to the instructions. After 2-h incubation, the lymphocyte proliferation absorbance was measured at $450 \mathrm{~nm}$ with a microplate photometer. Each group had three replications, and each replication was measured once.

\section{Flow Cytometry Analysis}

At weeks 0, 2, and 4, five mice from each group (before immunization and challenge) were euthanized to obtain the splenic as described in the section Determination of Lymphocyte Proliferation. The splenic lymphocytes were divided into several parts. For the maturation detection of dendritic cells (DCs), the splenic lymphocytes were cultured in DMEM containing 10\% FBS and $1 \%$ double antibiotics for $12 \mathrm{~h}$, and the non-adhering cells were discarded. After the plate was washed three times using PBS, the attached cells were collected by pipetting repeatedly and gently. Cells were then stained with anti-mouse CD11c-APC, CD86FITC, and CD83-PE (eBioscience, San Diego, CA, USA). To investigate the MHC molecule changes in DCs, the splenic lymphocytes were stained with anti-mouse CD11c-PE, MHC-IFITC, and MHC-II-APC (eBioscience, San Diego, CA, USA). To analyze the percentages of $\mathrm{CD} 4^{+} \mathrm{T}$ lymphocyte subsets, the splenic lymphocytes were stained with anti-mouse CD3e-PE and CD4FITC (eBioscience, San Diego, CA, USA). To detect the percentages of $\mathrm{CD}^{+} \mathrm{T}$ lymphocyte subsets, the splenic lymphocytes were stained with anti-mouse CD3e-PE and CD8FITC (eBioscience, San Diego, CA, USA). All stained procedures were conducted at $4^{\circ} \mathrm{C}$ for $40 \mathrm{~min}$. After centrifugation, collection, and washing, cells were sorted by a flow cytometry (Beckman Coulter Inc, Brea, CA, USA). Each group had five replications, and each replication was measured once.

\section{Parasite Burdens in Mice}

To determine the parasitic loads in mice, $30 \mathrm{mg}$ of specific tissue obtained in the section Immunization and Challenging Schedules in Mice was used for genomic DNA extraction and qPCR as described in the section Quantification of T. gondii in Tissue. Each group had five replications, and each replication was performed in triplicate; the recombinant vectors with a known copy number were also conducted in triplicate.

\section{Data Analysis}

Significance analysis was conducted by the SPSS 25.0 software (SPSS Inc., Chicago, IL, USA) and GraphPad 6.0 software (GraphPad Prism, San Diego, CA, USA). Based on one-way analysis of variance (ANOVA), differences between groups were considered as significant at $p<0.05$. Based on the homogeneity of variance, values between the TgSDRO-pVAX1/CS and TgSDRO-pVAX1/PLGA groups were compared with the independent $t$-test. The flow cytometric analysis was illustrated by the CytExpert software (version 2.3, Beckman Coulter Inc, Brea, CA, USA).

\section{RESULTS}

\section{Recombinant Plasmids Construction and Expression}

The recombinant plasmid TgSDRO-pVAX1 was successfully constructed as mentioned above. To verify the recombinant plasmid, an enzyme digestion was performed with EcoRI and XhoI, yielding two fragments of 1,119 and 2,966 bp (Figure 1A). The sequence analysis also proved that the insert in the recombinant plasmid was the ORF of TgSDRO. Together, all these results indicate that the recombinant plasmid was constructed correctly.

The endotoxin free DNA plasmids were purified by a commercial kit, and the endotoxin level of purified TgSDROpVAX1 plasmids fell to $0.1 \mathrm{EU} / \mathrm{ml}$. Then, immunofluorescence assay was conducted to evaluate the in vitro expression of TgSDRO-pVAX1 at $72 \mathrm{~h}$ after transfection of HEK 293-T cells. Cells transfected with TgSDRO-pVAX1 showed specific red fluorescence, whereas cells transfected with pVAX1 did not display red fluorescence (Figure 1B). The western blotting 
results revealed a single band (approximately $41 \mathrm{kDa}$ ) of the expected molecular size $(40.37 \mathrm{kDa})$, and no protein band was observed in cells transfected with the empty pVAX1 vector (Figure 1C). All these findings indicated that recombinant TgSDRO protein was expressed in HEK 293-T cells.

\section{Physical Characterization}

The SEM images showed that both TgSDRO-pVAX1/PLGA and TgSDRO-pVAX1/CS nanospheres were spherical in shape with round convex particles in the surface (Figure 2). The mean diameter of TgSDRO-pVAX1/PLGA nanospheres formed using $6 \%$ PVA was about $100.96 \pm 21.58 \mathrm{~nm}(\mathrm{n}=5)$, while the mean diameter of TgSDRO-pVAX1/CS nanospheres formed using 2 $\mathrm{mg} / \mathrm{ml}$ TPP was about $115.77 \pm 24.87 \mathrm{~nm}(\mathrm{n}=5)$. Based on five independent trails, the EE and LC of TgSDRO-pVAX1/PLGA nanosphere formulation reached $67.39 \%$ and $4.38 \%$ with the concentration of plasmids at $1 \mathrm{mg} / \mathrm{ml}$, while those were $82.42 \%$ and $1.23 \%$ in TgSDRO-pVAX1/CS nanosphere formulations. Preserved at least 3 months (Figures 2C, D), TgSDRO-pVAX1/ CS and TgSDRO-pVAX1/PLGA nanospheres were similar with those prepared freshly in morphologic characteristics. This finding suggested that both freeze-dried TgSDRO-pVAX1/CS and TgSDRO-pVAX1/PLGA nanospheres could keep the integrality over a long period of time at $4^{\circ} \mathrm{C}$.

\section{Release Characteristics}

By using a nanodrop microvolume spectrophotometer, the release characteristics of TgSDRO-pVAX1/PLGA and TgSDRO-pVAX1/CS nanospheres were further evaluated. TgSDRO-pVAX1/CS nanospheres showed a more favorable release profile compared to TgSDRO-pVAX1/PLGA nanospheres (Figure 3). Only $15.75 \pm 4.19 \%$ of the antigens were released from TgSDRO-pVAX1/CS nanospheres immediately and slowly released over the following days, finally reaching $82.58 \pm 6.79 \%$. A quickly releasing phase of
TgSDRO-pVAX1/PLGA nanospheres could be observed approximately during the first week with the initial CR at 7.09 $\pm 2.98 \%$; then the release profile became flat and finally reached $90.50 \pm 6.28 \%$ in the following days.

\section{Quantification of T. gondii in Tissues}

To determine T. gondii infection in different tissues, PCR amplification was conducted based on the ITS-1 sequence. As described in Figure 4A, T. gondii was observed in the intestine, heart, liver, spleen, and lung, while the leg muscle, brain, and kidney tissue were not detected. To determine the amount of T. gondii in different tissues, absolute qPCR was conducted based on the 529 bp repeat element. Before qPCR amplification, the OD260/OD280 value of each sample was quantified, and all samples were in the range of 1.6-1.8. As illustrated in Figure 4B, the concentration of $T$. gondii reached a maximum in the intestine tissue $\left(35.055 \times 10^{6}\right.$ copies $\left./ \mu \mathrm{l}\right)$, followed by heart $\left(25.179 \times 10^{6}\right.$ copies $\left./ \mu \mathrm{l}\right)$, lung $\left(14.085 \times 10^{6}\right.$ copies $\left./ \mu \mathrm{l}\right)$, liver $\left(4.529 \times 10^{6}\right.$ copies $\left./ \mu \mathrm{l}\right)$, and spleen tissue $\left(3.706 \times 10^{6}\right.$ copies $\left./ \mu \mathrm{l}\right)$.

\section{Antibodies and Cytokine Production in Mice}

The titers of total IgG, IgG1, and IgG2a induced in mice were measured by standard ELISA procedure. Demonstrated in Figure 5A, enhanced secretions of total IgG antibodies were obtained significantly in TgSDRO-pVAX1, TgSDRO-pVAX1/ CS, and TgSDRO-pVAX1/PLGA after the first (week 2) and booster (week 4) immunization. Mice immunized with TgSDRO-pVAX1/CS could generate the highest titer of total IgG after the second immunization (week 4). Compared with the blank and control group, mice immunized with TgSDROpVAX1, TgSDRO-pVAX1/CS, and TgSDRO-pVAX1/PLGA could generate higher titers of isotype IgG1 (Figure 5B) and IgG2a (Figure 5C) after the first and second immunizations.
A

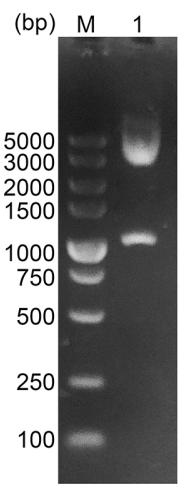

B
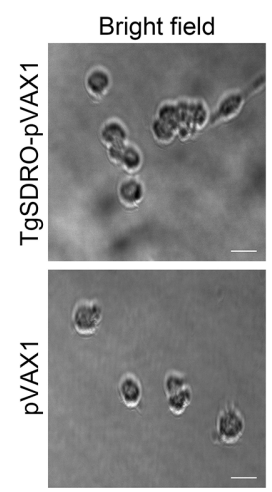

DAPI
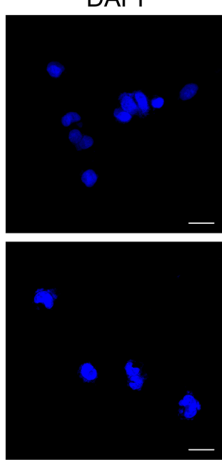
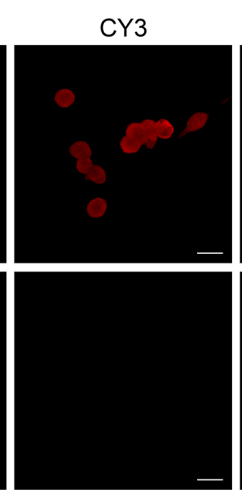
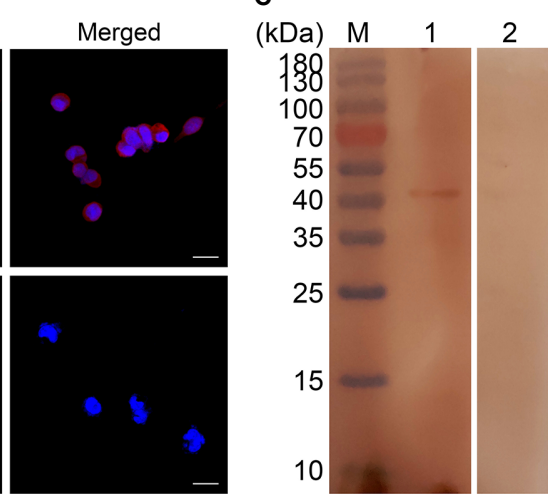

FIGURE 1 | (A) Double digestion analysis of the recombinant plasmid TgSDRO-pVAX1. Line M: DL5000 marker; Line 1: Double digestion with EcoRI and Xhol. (B) Immunofluorescence analysis of the expression of TgSDRO-pVAX1 in HEK 293-T cells. Bar represented $25 \mu \mathrm{m}$. (C) Western blot was conducted to detect the expression of TgSDRO in HEK 293-T cells. Cell lysates of HEK 293-T cells transfected with TgSDRO-pVAX1 (Line 1) and pVAX1 (Line 2) detected by sera from T. gondii-infected rats. Line M: molecular weight (MW) marker proteins. 
A

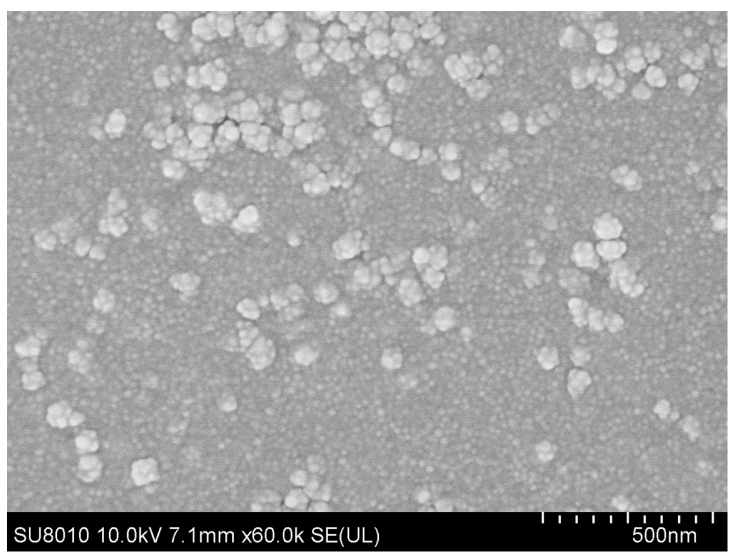

C

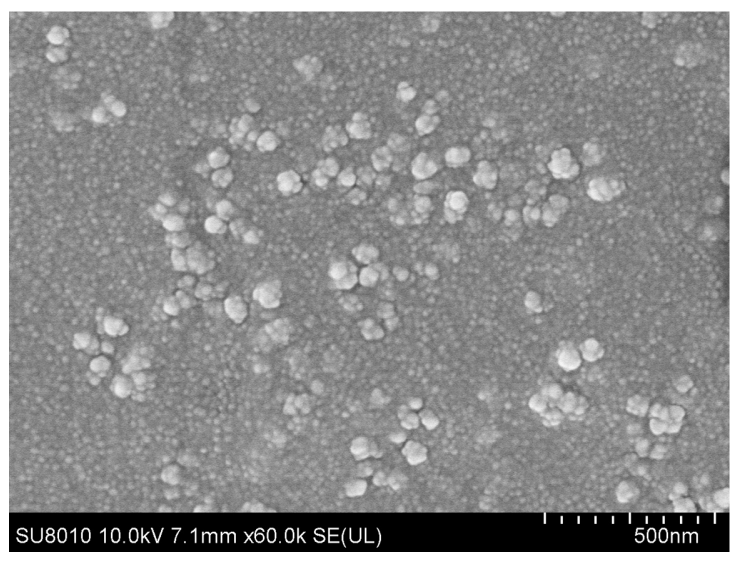

B

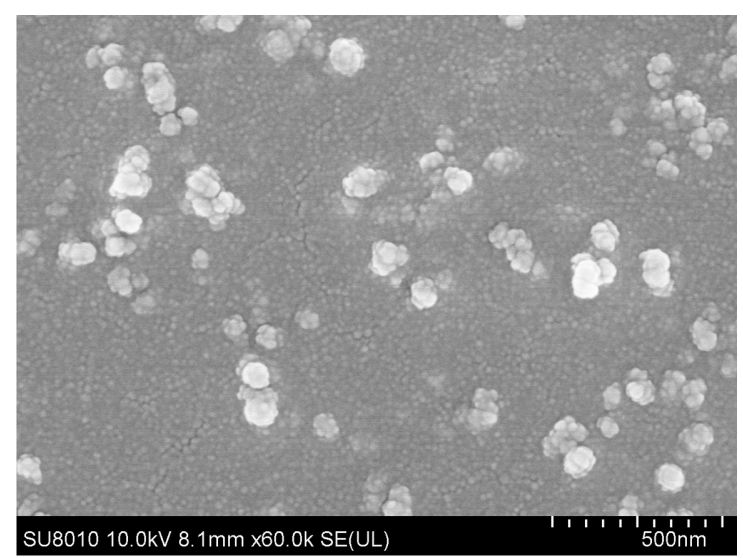

D

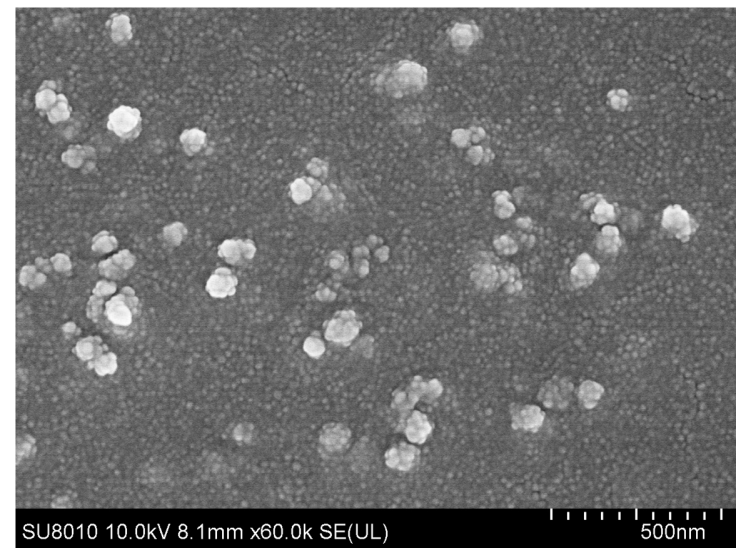

FIGURE 2 | The morphology of TgSDRO-pVAX1/PLGA and TgSDRO-pVAX1/CS nanospheres. Freshly prepared TgSDRO-pVAX1/PLGA nanospheres (A) and those preserved over 3 months (C) were synthetized by a double emulsion solvent evaporation technique, while newly prepared TgSDRO-pVAX1/CS nanospheres (B) and those preserved over 3 months (D) were prepared by an ionic gelation technique (bar represented $500 \mathrm{~nm}$ ).

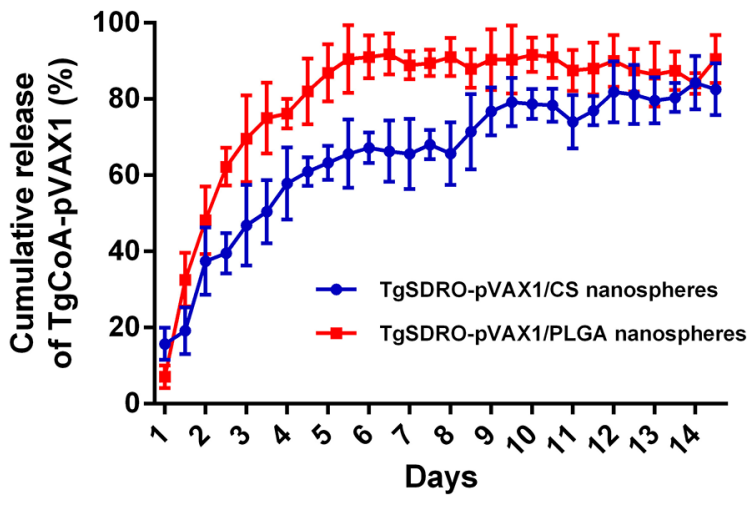

FIGURE 3 | The release profile of TgSDRO-pVAX1/PLGA and TgSDROpVAX1/CS nanospheres in vitro over a 14-day period. Each sample was conducted once. Bar represents mean \pm SD $(n=3)$.
Furthermore, no significant difference $(p>0.05)$ was evaluated in the TgSDRO-pVAX1/CS and TgSDRO-pVAX1/PLGA groups.

Strictly following the instruction, the concentrations of IFN- $\gamma$, IL-4, IL-10, and IL-17 in the sera were determined by commercial ELISA kits based on the double antibody sandwich method. As demonstrated in Figures 6A, B, remarkable increases could be observed in the TgSDRO-pVAX1/CS and TgSDRO-pVAX1/PLGA groups after the first immunization (week 2), while the TgSDRO-pVAX1 group remained unchanged $(p>0.05)$. After the second immunization (week 4 ), all mice from the treatment group could generate a significant $(p<0.001)$ level of IFN- $\gamma$, and mice immunized with TgSDROpVAX1/CS and TgSDRO-pVAX1/PLGA could generate a significant $(p<0.01)$ level of IL-4. As for IL-17 showed in Figure 6D, significant secretions can be obtained in mice immunized with TgSDRO-pVAX1 and TgSDRO-pVAX1/CS after the first immunization, and after the second immunization, secretions of IL-17 were significantly enhanced 
A

B

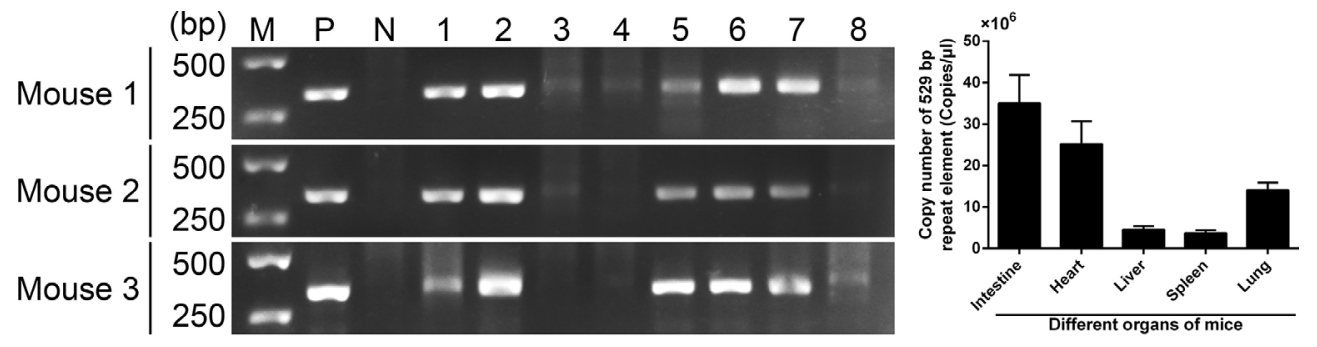

FIGURE 4 | T. gondii detection in mouse tissues 7 days after infection. (A) T. gondii was detected by PCR based on ITS-1 sequence. Line M: DL5000 marker; Line P: positive control; Line N: negative control; Line 1-10: intestine, heart, leg muscle, brain, liver, spleen, lung, and kidney tissue. (B) T. gondii was detected by absolute qPCR based on a 529 bp repeat element. Results were showed as mean $\pm S D(n=3)$.

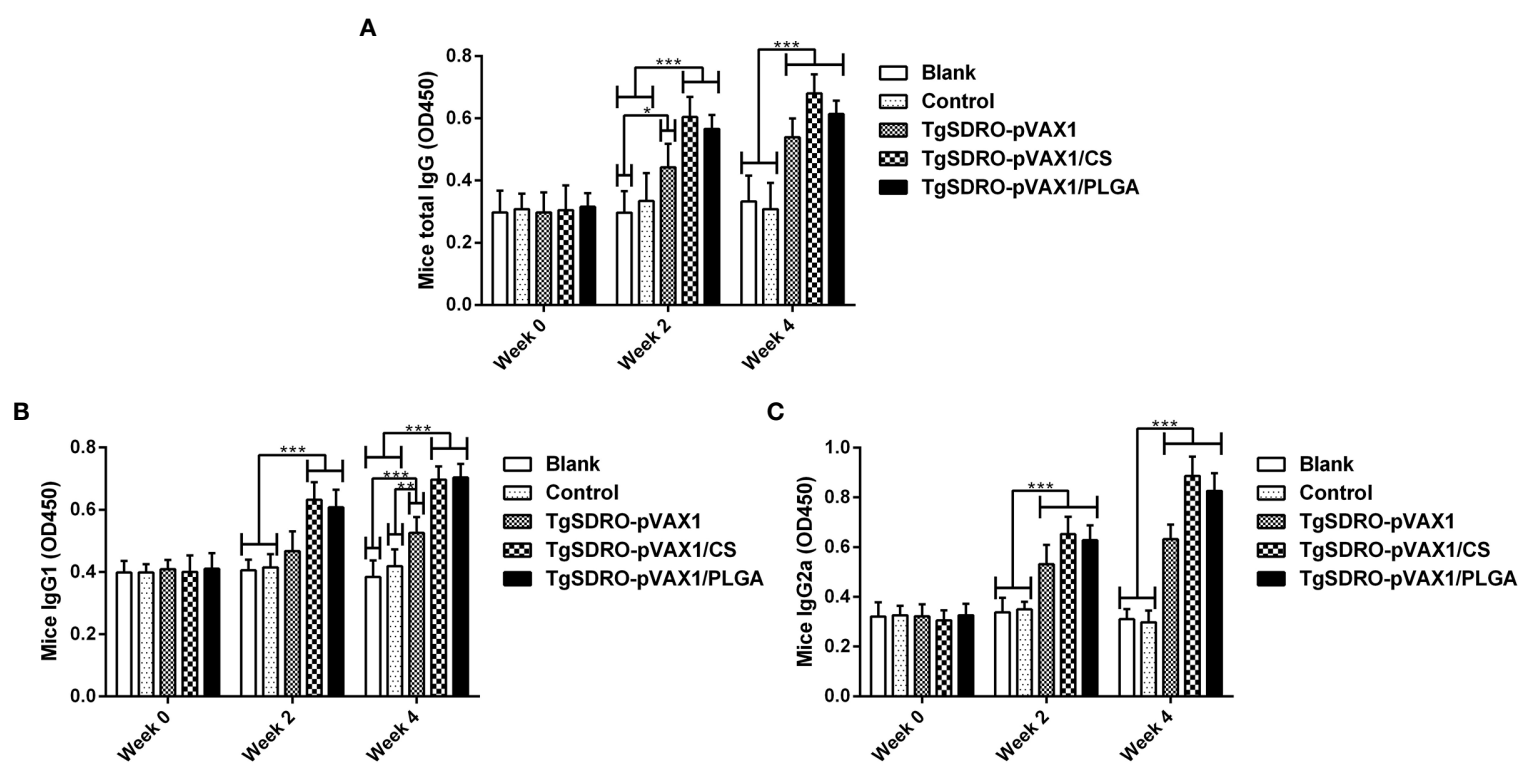

FIGURE 5 | Immunoglobulin determination of total lgG (A), isotypes lgG1 (B), and lgG2 (C) in the sera from immunized mice at weeks 0 , 2, and 4. Each sample was conducted once, and values were estimated using one-way ANOVA followed by Dunnett's test and shown as the mean of the OD450 \pm SD ( $n=5$ ). Values between the TgSDRO-pVAX1/CS and TgSDRO-pVAX1/PLGA groups were compared with the independent $t$-test. ${ }^{*} p<0.05,{ }^{\star *} p<0.01$, and ${ }^{\star \star *} p<0.001$ compared with the blank or control group.

in all treatment groups. Furthermore, equivalent IL-10 $(p>0.05$, Figure 6C) secretions were observed in all immunized animals.

\section{Flow Cytometry Analysis in Dendritic Cells}

The expression of CD83 and CD86 on DCs was examined by flow cytometry. After the first and second immunizations (Figures 7A, C), treatment with TgSDRO-pVAX1, TgSDROpVAX1/CS, and TgSDRO-pVAX1/PLGA showed significant improvements in the percentage of $\mathrm{CD} 11 \mathrm{c}^{+} \mathrm{CD} 83^{+}$cells when compared with the blank or control group. Furthermore, statistical improvements in the percentage of $\mathrm{CD} 11 \mathrm{c}^{+} \mathrm{CD} 86^{+}$ cells could be detected in the TgSDRO-pVAX1/CS and TgSDRO-pVAX1/PLGA groups (Figures 7B, C) after the first and second immunizations. Noticeably, no statistical difference
( $p>0.05)$ was revealed between the TgSDRO-pVAX1/CS and TgSDRO-pVAX1/PLGA groups in DC maturation analysis.

In order to investigate the percentage of MHC molecules on splenic DCs, five mice from each group were sacrificed, and the spleen lymphocytes were analyzed. Described in Figures 8A, C, the ratio of MHC-I molecules in the TgSDRO-pVAX1/CS and TgSDRO-pVAX1/PLGA groups was enhanced after the first and second immunizations, while the TgSDRO-pVAX1 group remained unchanged $(p>0.05)$. For the ratio of MHC-II molecules in Figures 8B, C, significant enhancement was detected after the first and second immunizations. Furthermore, the statistics also revealed that mice immunized with TgSDRO-pVAX1/PLGA could generate significantly higher percentage $(p<0.001)$ of MHC-II molecules after a booster 


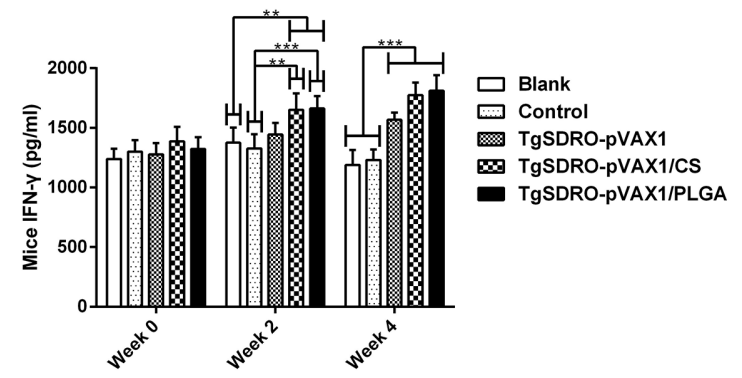

C
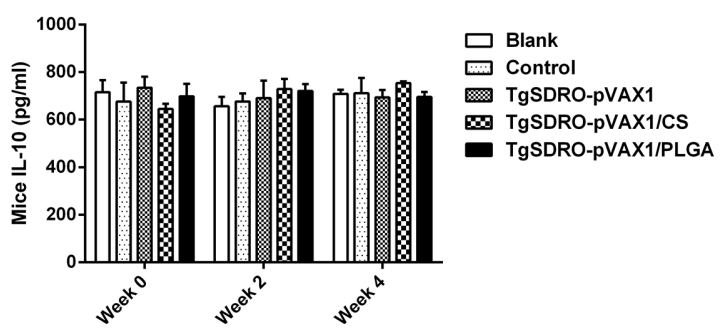

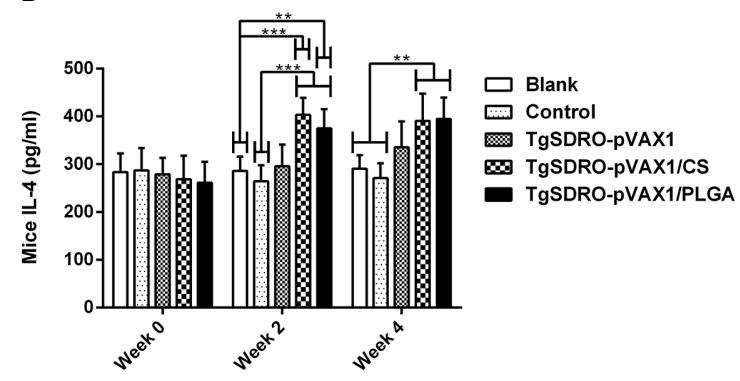

D

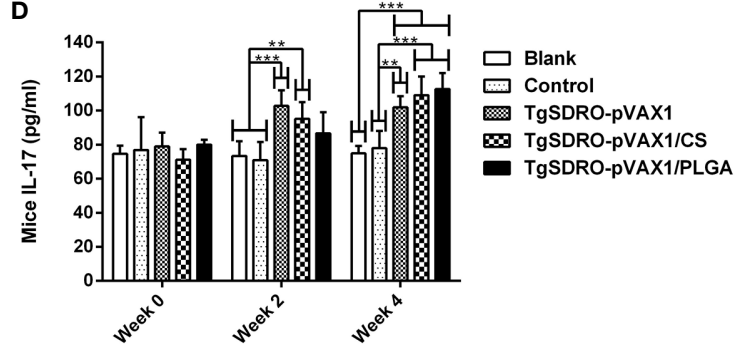

FIGURE 6 | The dynamics of cytokine production in immunized mice. The mice sera were collected at weeks 0 , 2, and 4, and the commercial ELISA kits were used to investigate the levels of IFN- $\gamma$ (A), IL-4 (B), IL-10 (C), and IL-17 (D) in mice sera. Each serum was investigated once. Results were estimated using one-way ANOVA tracked by Dunnett's test, and values were shown as mean $\pm \mathrm{SD}(\mathrm{n}=5)$. Based on the independent $t$-test, values between the TgSDRO-pVAX1/CS and TgSDRO-pVAX1/PLGA groups were compared. ${ }^{\star \star} p<0.01$ and ${ }^{* \star *} p<0.001$ compared with the blank or control group.

immunization compared to those immunized with TgSDROpVAX1/CS.

\section{Lymphocyte Proliferation}

Spleen lymphocytes were prepared from different groups 1 week after the second immunization, and the proliferative responses were analyzed. Evaluated in Figure 9, mice immunized with TgSDRO-pVAX1, TgSDRO-pVAX1/CS, and TgSDRO-pVAX1/ PLGA produced a significant $(p<0.001)$ proliferation when compared with the blank and control group. Moreover, the TgSDRO-pVAX1/PLGA group could generate a higher $(p<$ 0.05) proliferation than the TgSDRO-pVAX1/CS group.

\section{Flow Cytometry Analysis in T Lymphocytes}

Five mice from each group were sacrificed and the splenocytes were stained, then the percentages of $\mathrm{CD}^{+} \mathrm{T}$ and $\mathrm{CD}^{+} \mathrm{T}$ lymphocytes of each group were conducted. Illustrated in Figure 10A, the percentage of $\mathrm{CD}^{+} \mathrm{T}$ cells in the TgSDROpVAX1, TgSDRO-pVAX1/CS, and TgSDRO-pVAX1/PLGA groups was significantly increased at weeks 2 and 4 when compared with the blank and control group. In the case of the percentage of $\mathrm{CD}^{+} \mathrm{T}$ cells (Figure 10B), the TgSDRO-pVAX1, TgSDRO-pVAX1/CS, and TgSDRO-pVAX1/PLGA groups generated a significant increase when compared with the blank and control group at weeks 2 and 4 . For the percentages of $\mathrm{CD}^{+} \mathrm{T}$ and $\mathrm{CD}^{+} \mathrm{T}$ lymphocytes, mice in the TgSDRO-pVAX1/CS group could generate statistically similar $(p>0.05)$ to those in the TgSDROpVAX1/PLGA group after the first and second immunizations.

\section{Adverse Reaction and Parasite Burden in Animals}

The animals' health condition was investigated through the clinical observation, and the significant toxicity of nanospheres was not evaluated. All immunized animals were similar in physical health and stable in mental status over the duration of the trials compared with the animals immunized with PBS.

To obtain a more accurate analysis of parasite burden in mice, the method of absolute qPCR was conducted to detect the 529 bp repeat element of T. gondii in cardiac muscles from the tip of the heart. Before the qPCR amplification, the OD260/OD280 value of each sample was quantified, and all samples were in the range of 1.6-1.8. Presented in Figure 11, the parasite burden was significantly $(p<$ 0.001) inhibited in the TgSDRO-pVAX1, TgSDRO-pVAX1/CS, and TgSDRO-pVAX1/PLGA groups compared to the blank and control group. Furthermore, significance $(p<0.05)$ also could be observed in the 529 bp repeat element between the TgSDRO-pVAX1/CS and TgSDRO-pVAX1/PLGA groups.

\section{DISCUSSION}

It has been proved that nanosphere delivery systems can prevent antigens from degradation and enable co-immunization of antigens and immunomodulators to the same cell type $(50,51)$. Encapsulated in PLGA nanospheres, co-delivery of antigens along with toll-like receptor (TLR) ligands can result in the secretion of natural killer (NK) cell-activating cytokines (52), and the bias toward Th1 and 
A

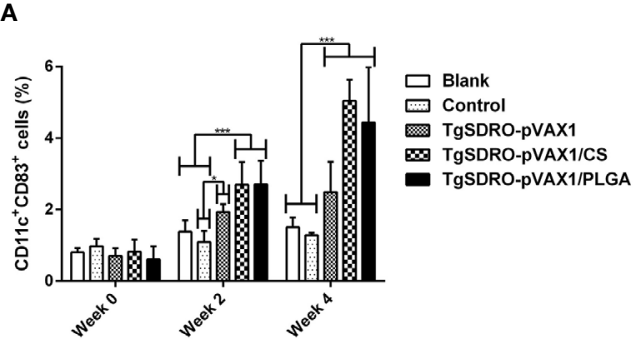

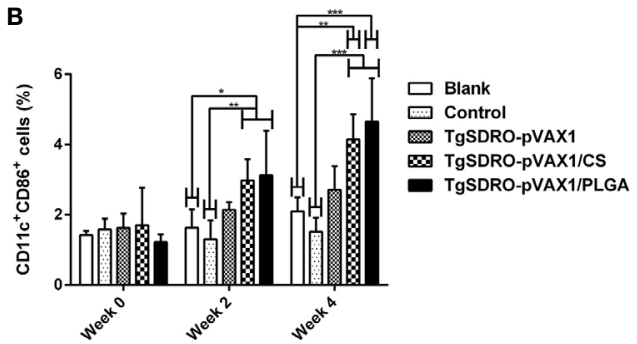

C

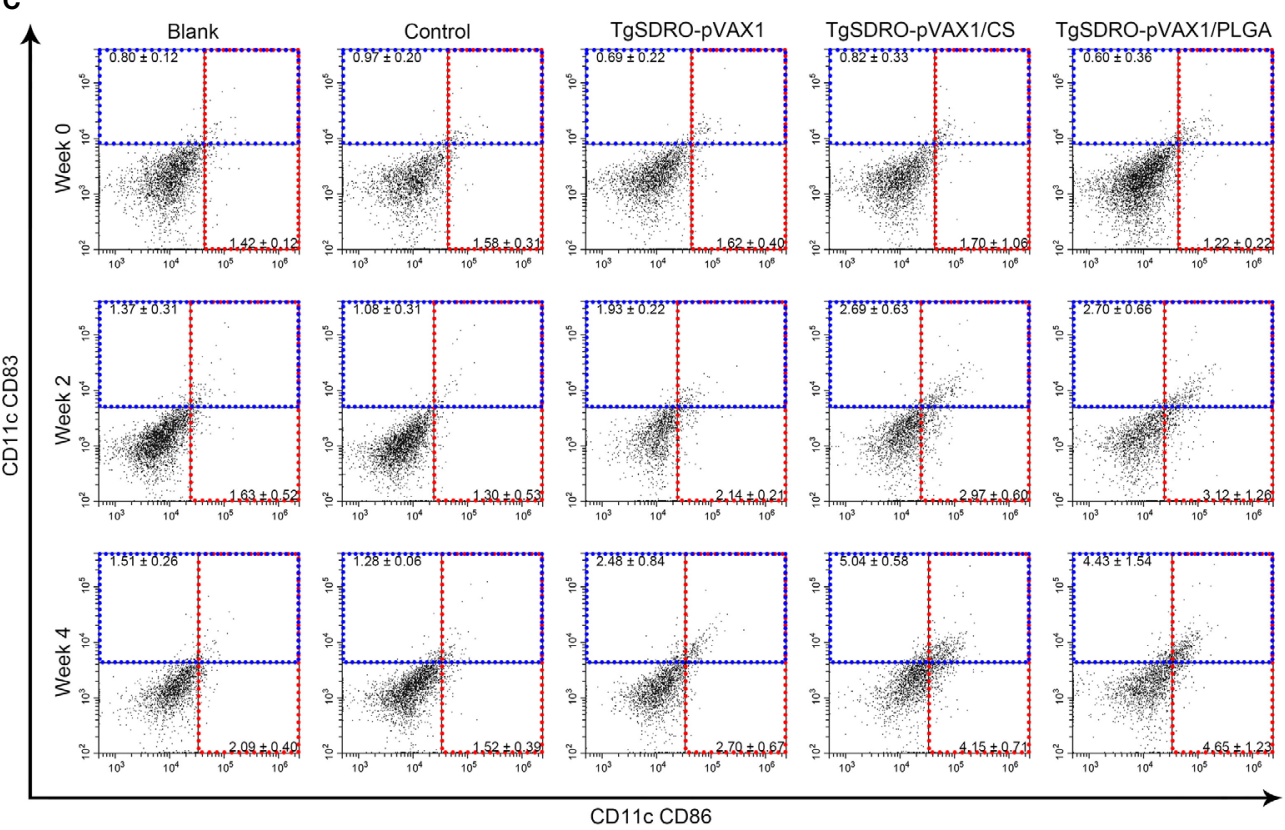

FIGURE 7 | Analysis of DC maturation at weeks 0,2 , and 4 by flow cytometry. Five mice in each group were sacrificed; the bar graph showed the ratio of CD83 (A) and CD86 (B) molecules on splenic DCs, and the dot plots (C) showed the percentage of CD11 $\mathrm{C}^{+} \mathrm{CD} 83^{+}$and $\mathrm{CD} 11 \mathrm{c}^{+} \mathrm{CD} 86^{+}$cells. Each sample was conducted once. Results were estimated by one-way ANOVA followed by Dunnett's test, and values were showed as mean \pm SD $(n=5)$. Values between the TgSDRO-pVAX1/CS and TgSDRO-pVAX1/PLGA groups were compared with the independent $t$-test. ${ }^{*} p<0.05,{ }^{* *} p<0.01$, and ${ }^{* * *} p<0.001$ compared with the blank group or the control group.

Th2 responses will be determined by the appropriate selection of TLR ligands (53). Unfortunately, the anionic nature of PLGA nanospheres can lead to their poor mucoadhesiveness (54), and the adjuvanticity can also be affected by their size, surface characteristics, or encapsulated antigens (55). By limiting nontarget immunity with the normal immune functions, chitosan nanospheres are considered as a powerful polymer candidate with high targeted immunogenicity $(56,57)$. Through the cyclic GMPAMP synthase (cGAS) stimulator of interferon genes (STING) pathway, chitosan has been illustrated to be effective in activating DCs and Th1 immune response (58). However, exhibiting a disadvantage for antigen delivery, the deacetylation of chitosan nanospheres can modify its solubility, its degradation, its hydrophobicity, and even its electrostatic interaction (59).

At present, many methods have been developed for the formulation of polymeric nanospheres against T. gondii based on different types of polymeric nanospheres. Different methods for developing polymeric nanospheres can affect the EE and LC, and $\mathrm{EE}$ is an important value to assess the quality of nanospheres. Chitosan nanospheres loaded with DNA vaccine synthetized by Zheng et al. (60) showed $92.8 \% \mathrm{EE}$ and $63.7 \% \mathrm{LC}$ with an average diameter of $145.5 \mathrm{~nm}$. Similar to the method used in this study, the EE of PLGA-NPs-pDNA nanospheres reached 57.50\% with an average diameter of $149.60 \mathrm{~nm}$ (61). The modified double emulsion solvent evaporation technique and ionic gelation technique were applied in the synthesis of PLGA and chitosan nanospheres at the present study, and the EE of TgSDRO-pVAX1/ CS and TgSDRO-pVAX1/PLGA nanospheres were $82.42 \%$ and $61.39 \%$, respectively. However, the LC of TgSDRO-pVAX1/CS and TgSDRO-pVAX1/PLGA nanospheres were $1.23 \%$ and $4.38 \%$, respectively. Such differences may be due to different methods, and further studies should be focused on the LC improvement of the 
A

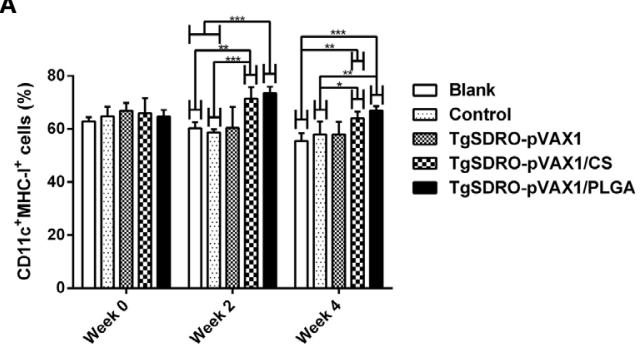

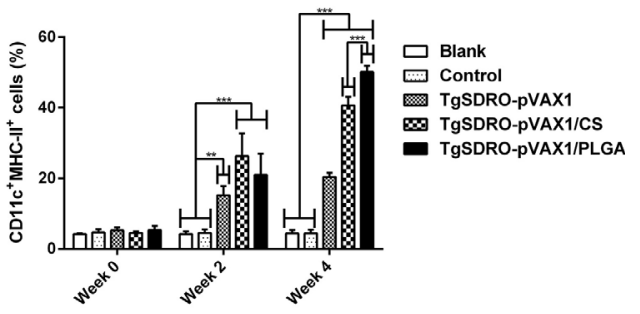

c
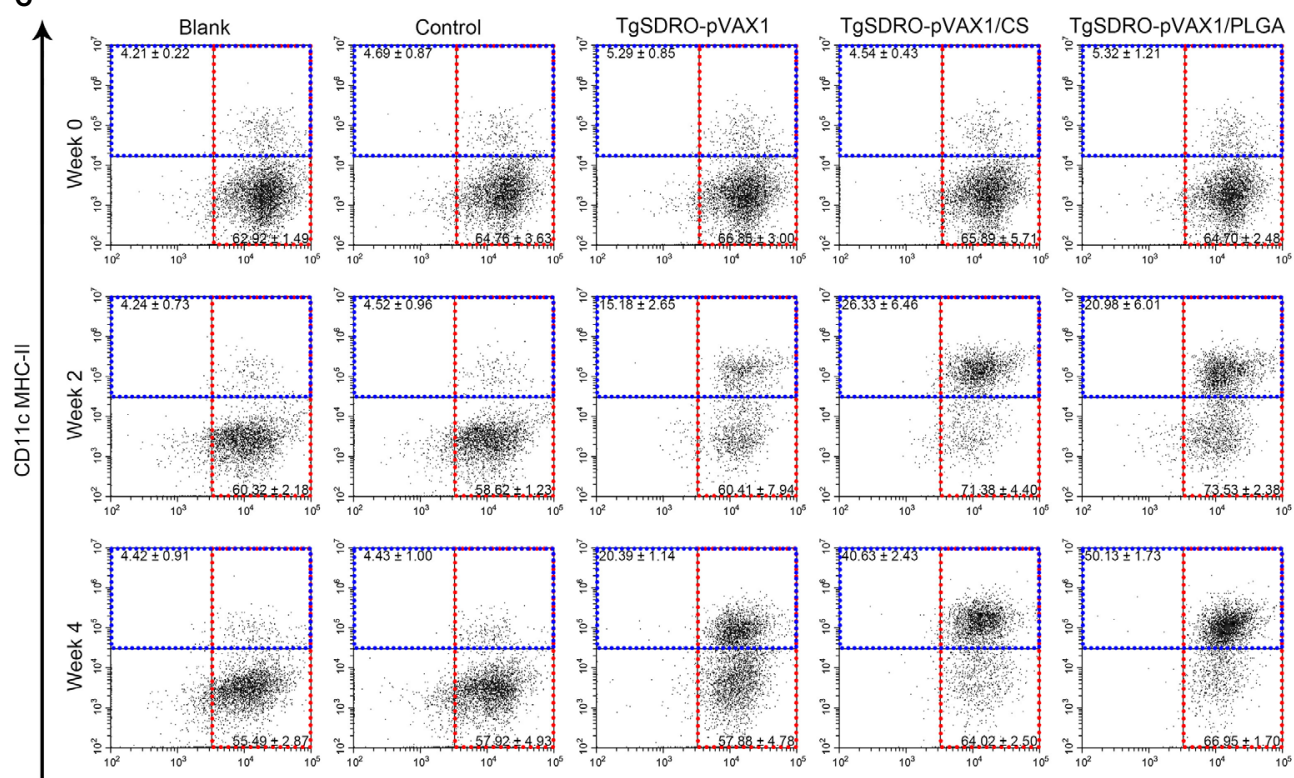
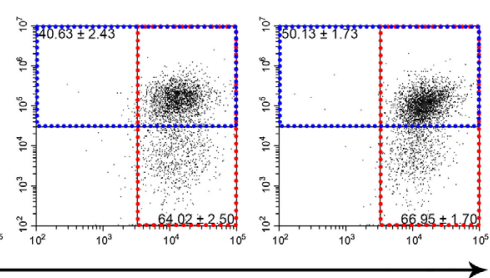

CD11c MHC-I

FIGURE 8 | Analysis of MHC molecules at weeks 0, 2, and 4 by flow cytometry. Five mice in each group were sacrificed; the bar graph showed the ratio of MHC-I (A) and MHC-II (B) molecules on splenic DCs, and the dot plots (C) showed the percentage of CD11 $\mathrm{C}^{+} \mathrm{MHC}-\mathrm{I}^{+}$and $\mathrm{CD} 11 \mathrm{C}^{+} \mathrm{MHC}-\mathrm{II}^{+}$cells. Each sample was conducted once. Results were estimated by one-way ANOVA followed by Dunnett's test, and values were showed as mean $\pm \mathrm{SD}$ ( $\mathrm{n}=5$ ). Values between the TgSDRO-pVAX1/CS and TgSDRO-pVAX1/PLGA groups were compared with the independent $t$-test. ${ }^{\star} p<0.05$, ${ }^{\star \star} p<0.01$, and ${ }^{\star \star \star} p<0.001$ compared with the blank group or the control group.

DNA vaccine. Furthermore, synthetized nanospheres were spherical with many convex structures on the surface and had an average diameter of around $100.96 \mathrm{~nm}$ (TgSDRO-pVAX1/CS nanospheres) and $115.77 \mathrm{~nm}$ (TgSDRO-pVAX1/PLGA nanospheres). Effected on the efficiency of target genes in transfection and expression, the diameter of nanospheres loaded with DNA vaccines is an important indicator in quality assessment (62, 63). Evaluated by Caco-2 cell lines, 100-nm-sized PLGA nanospheres provided a better uptake, showing 2.5 times higher uptake than 1,000-nm-sized nanospheres (64). The TgSDROpVAX1/CS and TgSDRO-pVAX1/PLGA nanospheres prepared in the present study were approximately $100 \mathrm{~nm}$, which could contribute to the entrance of DNA vaccine into cells. As already proved, the residual moisture content often affects the stability and integrity of nanospheres both physically and chemically during a long-term preservation (65). Hence, thorough freeze-drying is a promising approach to better stabilize the antigen against degradation. However, lyophilization can generate a series of drying and freezing stresses, which could denature antigens to various degrees (66). Thus, subsequent studies are required in nanosphere formulation to protect the stability of antigens during both drying and freezing processes. Furthermore, the repeatability in nanosphere synthesis is a nonnegligible factor in clinic application. In the present study, two types of nanospheres were synthesized multiple times, and relevant characteristics were conducted according to various batches of nanospheres. However, this preparation does not represent a reliable synthesis method, and further studies are required.

As delivery vehicles, effective nanospheres can provide protection of entrapped antigens against undesirable degradation during transportation to target cells (67). Through a slow hydrolysis process, PLGA nanospheres could release their 


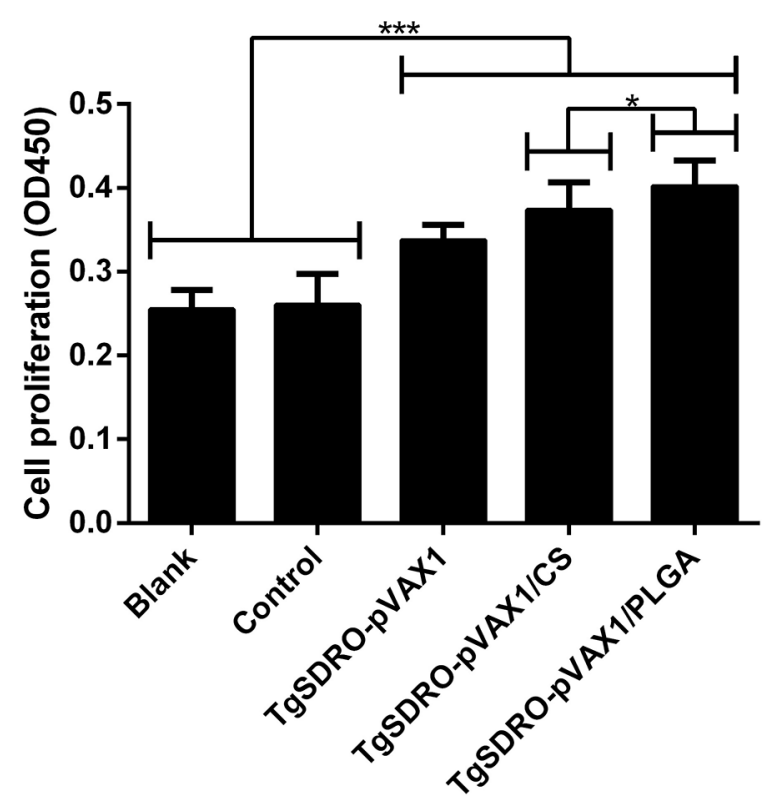

FIGURE 9 | Splenocyte proliferation of different immunized mice. Three mice in each group were sacrificed, and spleen lymphocytes of each mouse were divided into four samples; the spleen lymphocytes were cultured using the medium from HEK 293-T lysate transfected with PBS (blank group), pVAX1 blank plasmid (control group), TgSDRO-pVAX1 recombinant plasmid (TgSDRO-pVAX1, TgSDRO-pVAX1/CS, and TgSDRO-pVAX1/PLGA groups). Each sample was measured once, and the bar graph was evaluated by oneway ANOVA followed by Dunnett's test; values were showed as mean $\pm \mathrm{SD}$ $(n=3)$. Values between the TgSDRO-pVAX1/CS and TgSDRO-pVAX1/PLGA groups were compared with the independent $t$-test. ${ }^{\star} p<0.05$ and ${ }^{\star \star \star} p<$ 0.001 compared with the blank group or the control group.

antigens with a burst release making the antigens to be quickly released in a short time (34). In addition, negatively charged chitosan nanospheres could form polymer-plasmid complexes by adhering to the cell surface, leading to a continuous payload release (68). In the present study, a steadier release profile of TgSDRO-pVAX1/CS nanospheres was obtained in comparison with TgSDRO-pVAX1/PLGA nanospheres. A steady release curve does not mean an effective delivery system for drugs or vaccines; notably, efficient nanospheres are often limited by the toxicity and the difficulty in preparing them (20). During the preparation of TgSDRO-pVAX1/CS and TgSDRO-pVAX1/ PLGA nanospheres in this study, DCM used in the synthesis of PLGA nanospheres has been thought to be toxic and hard to remove thoroughly by evaporation at room temperature (69). To avoid toxicity, TgSDRO-pVAX1/PLGA nanospheres were completely lyophilized. As expected, TgSDRO-pVAX1/CS and TgSDRO-pVAX1/PLGA nanospheres did not show adverse reactions based on the clinical observations.

In a previous paper, the predilection tissue of $T$. gondii has been previously described in the heart of pigs (70), and another paper revealed that the lung and heart were detected to have a high parasite burden in pig models of $T$. gondii infection (71). However, the animals used to illustrate these results were infected orally, and no published paper reveals the predilection tissue of $T$. gondii in mice through intraperitoneal challenges. Based on the results in the present study, the intestine, heart, and lung tissue were detected to have a higher parasite burden compared to the liver and spleen tissue. As it had the highest parasitic loads infected with oocysts in previous studies $(70,72)$, the heart tissue was negative in PCR amplifications; such results may be due to different infection ways. Although the intestine tissue owned the highest parasite burden among all investigated tissues, the heart muscles were selected for the subsequent trials mainly due to the potential contamination of challenged T. gondii in the intestine tissue.

Associated with inhibiting cell absorption and promoting macrophage killing of $T$. gondii, it has been long recognized that humoral response plays a critical role in immune protection against T. gondii infection (73). In the present study, immunized mice could gradually generate high levels of total IgG, IgG1, and IgG2a. According to a published paper, high levels of total IgG are critical in anti- $T$. gondii infections and depressing cyst reactivation (74). In addition, the subclass IgG1 is associated with Th2-related immunity, and Th1-biased response is associated with subclass IgG2a $(47,75)$. Our results also indicated that two types of nanospheres could generate Th1biased immune response with the IgG2a/IgG1 value higher than one after a boost immunization. Similar to our results, Th1biased immune response was also illustrated in $\mathrm{BALB} / \mathrm{c}$ mice vaccinated with pEGFP-N1-HBsAg-GRA1-ROP2 plasmids (17). Playing an important role in resisting intracellular infection, Th1-biased immunity has been proved essential in anti-T. gondii infections $(76,77)$.

Cytokines are critical in mediating the T helper (Th) cells, and enhanced secretion of Th1 cytokines plays an essential role in resisting $T$. gondii (78). Increased secretion of IFN- $\gamma$ can depress the replications of $T$. gondii through activating phagocytes $(79,80)$. Compared with the blank and control group, animals from the vaccinated group were observed to have Th1 biased immunity by generating a higher level of IFN- $\gamma$ after the second immunization. According to a published paper, the early mortality of acute toxoplasmosis is mainly induced by severe inflammation rather than T. gondii (81). Thus, cytokines IL- 4 and IL-10 were conducted. As the factor of Th2 biased immunity, IL- 4 could induce the secretion of IgG1 (82). A significant enhancement of cytokine IL-4 was observed in immunizations with two types of nanospheres. However, the level of IL-10 remained similar in all vaccinated groups. Together with the results of antibodies, these results demonstrated that TgSDRO-pVAX1/CS and TgSDRO-pVAX1/ PLGA nanospheres could elicit both Th1 and Th2 immune responses and mainly skewed to a Th1 biased immunity, which played a critical role in cell-mediated immunity and T. gondii resistance $(83,84)$. In addition, as an inflammatory modulator produced by Th17 (85), cytokine IL-17 is also important in anti-T. gondii infections $(86,87)$. In the present study, animals from the vaccinated group were observed to have significantly higher levels of IL-17 after a booster immunization, indicating that TgSDRO-pVAX1 and its 
A
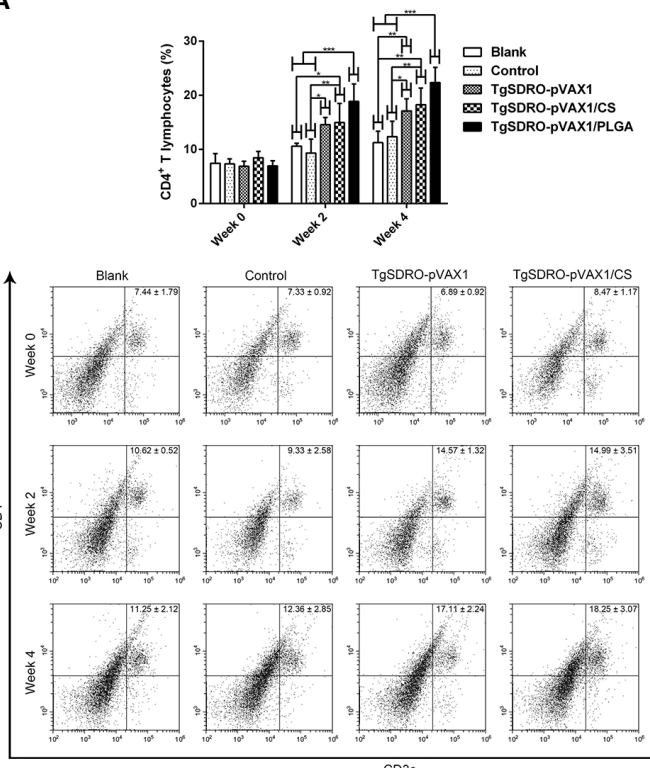
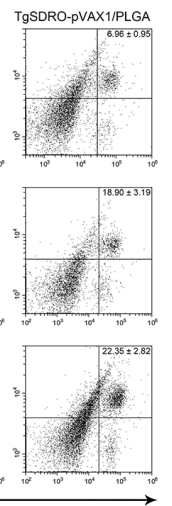

B
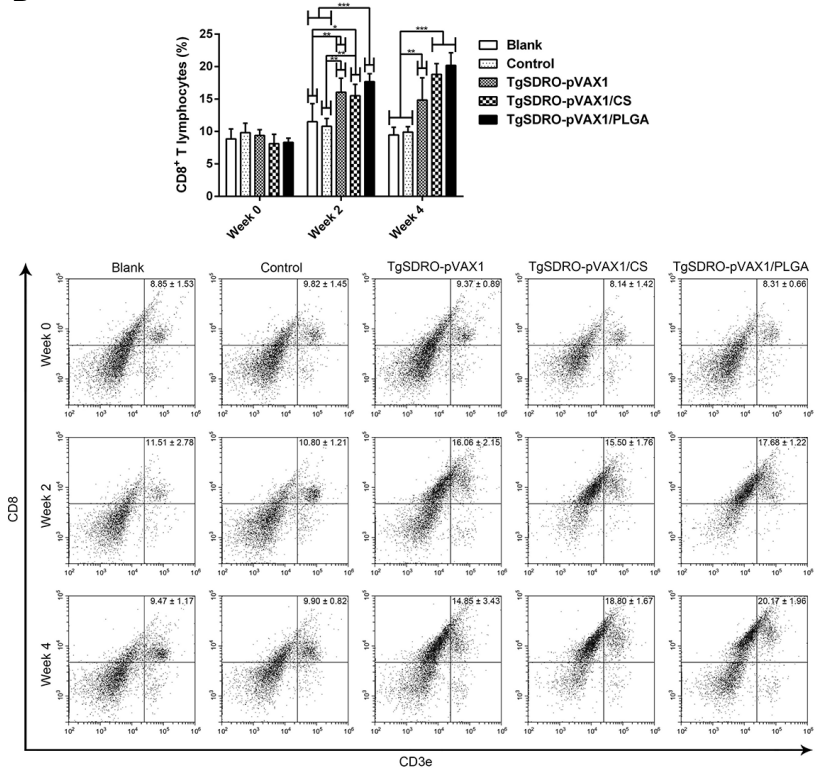

FIGURE 10 | The proportions of $\mathrm{CD} 4^{+}$and $\mathrm{CD} 8^{+} \mathrm{T}$ lymphocytes in all groups. Five mice in each group were sacrificed, and spleen lymphocytes from each animal were stained with CD3e-PE, CD4-FITC (A) or CD3e-PE, CD8-FITC (B). Determined by flow cytometry, each sample was conducted once. Results were estimated by one-way ANOVA followed by Dunnett's test, and values were showed as mean $\pm S D(n=5)$. Values between the TgSDRO-pVAX1/CS and TgSDRO-pVAX1/ PLGA groups were compared with the independent $t$-test. ${ }^{\star} p<0.05,{ }^{* *} p<0.01$, and ${ }^{\star \star *} p<0.001$ compared with the blank group or the control group.

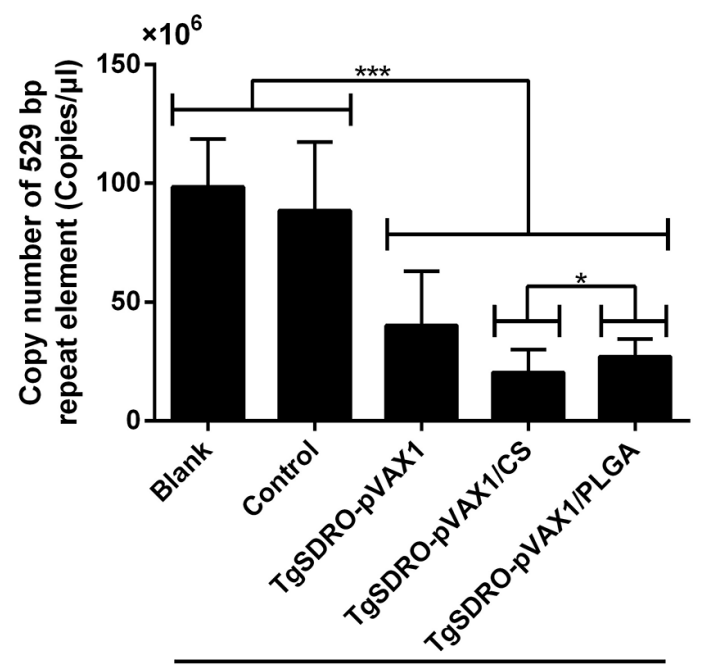

Challenged with $T$. gondii

FIGURE 11 | Copy number of a 529 bp repeat element in cardiac muscles from mice. Mice were intraperitoneally injected with $10^{3}$ tachyzoites of the highly virulent $T$. gondii RH strain at week 4 (2 weeks after the last immunization). Seven days after the challenge, five mice in each group were sacrificed, and cardiac muscles from the tip of the heart were collected. Each sample was performed three times. Results were evaluated using one-way ANOVA followed by Dunnett's test, and the values were shown as mean \pm SD $(n=5)$. Values between the TgSDRO-pVAX1/CS and TgSDRO-pVAX1/ PLGA groups were compared with the independent $t$-test. ${ }^{*} p<0.05$ and ${ }^{* \star *} p<0.001$ compared with the blank group or the control group. nanospheres were capable of triggering Th17 differentiation and involved in anti- $T$. gondii infections.

Being capable of antigen capturing and processing, DCs can efficiently activate naïve $\mathrm{T}$ cells against antigens and polarize them to different effector fates $(88,89)$. Immature DCs are poor activators and ineffective in T lymphocyte-stimulating activity, while the activity boosts hugely when DCs receive a maturation signal (90). When receiving a maturation signal, DCs experience massive changes, mainly including enhanced surface molecule expression critical for T lymphocyte activation, such as MHC-II, CD40, and CD86 (91). Furthermore, as a typical surface marker, CD83 was expressed in mature DCs and other cells and used as an immune checkpoint (92). In the present study, we obtained the differences in the relative percentages of $\mathrm{CD} 11 \mathrm{c}^{+} \mathrm{CD} 83^{+}$and $\mathrm{CD} 11 \mathrm{c}^{+} \mathrm{CD} 86^{+}$cells among the vaccinated, blank, and control groups. These findings indicated that TgSDRO-pVAX1/CS and TgSDRO-pVAX1/PLGA nanospheres could accelerate the maturation of DCs and launch their functions.

As the most effective antigen-presenting cells (APCs), DCs could evoke the innate and adaptive immune response and are critical in the interaction between two types of immunity (93, 94). To perform antigen-presenting functions, DCs have evolved MHC-II proteins, which could load processed antigens (95). Then antigen-MHC-II complexes are transported to the surface of cells, where they can be recognized by $\mathrm{CD} 4^{+} \mathrm{T}$ lymphocytes. Evidence from previous studies suggested that MHC-II could be critical in eliciting strong immune response $(96,97)$. In the present study, significantly higher percentages of $\mathrm{CD} 11 \mathrm{c}^{+} \mathrm{MHC}$ $\mathrm{I}^{+}$and $\mathrm{CD} 11 \mathrm{c}^{+} \mathrm{MHC}-\mathrm{II}^{+}$cells were evaluated in two types of 
nanospheres compared with the blank or control group. As a critical molecule in endogenous antigen-presenting cells, MHC-I could induce strong $\mathrm{CD}^{+} \mathrm{T}$ lymphocyte immunity (98). Furthermore, the promoted expression of MHC-I might be due to the high level of IFN- $\gamma$. Previous studies suggested that IFN- $\gamma$ could enhance the MHC-I expression and antigen presentation by activating the Janus kinase/Signal transducer and activator of transcription 1 (JAK/STAT1) pathway $(99,100)$. To sum up, these results suggested that TgSDRO-pVAX1/CS and TgSDROpVAX1/PLGA nanospheres could activate the MHC-II restricted and MHC-I restricted antigen presentation.

The lymphocyte proliferation was regarded as the most efficient index in reflecting the status of immunity in vivo (101). In the present study, we observed remarkable differences in lymphocyte proliferation between the vaccinated, blank, and control groups. Furthermore, the proliferation ability from animals immunized with TgSDRO-pVAX1/PLGA nanospheres was significantly enhanced compared with animals immunized with TgSDRO-pVAX1/CS nanospheres. These findings indicated that both TgSDRO-pVAX1/CS and TgSDROpVAX1/PLGA nanospheres could effectively promote the proliferation of lymphocytes, and the PLGA delivery vehicle was more efficient.

Due to the intracellular inhibition of T. gondii, T lymphocyte activation is critical in resisting the replications of $T$. gondii, especially the $\mathrm{CD}^{+}$and $\mathrm{CD} 8^{+} \mathrm{T}$ lymphocytes (102). Previous studies have revealed that $\mathrm{CD} 4^{+} \mathrm{T}$ lymphocytes are essential in mediating immunity against toxoplasmosis, while $\mathrm{CD}^{+} \mathrm{T}$ lymphocytes play an important role in the cytotoxic effect $(103,104)$. In addition, $\mathrm{CD}^{+} \mathrm{T}$ lymphocytes play an essential role in formulations of memory $\mathrm{CD}^{+} \mathrm{T}$ lymphocytes after immunizations or infections (105). In the present study, the percentages of $\mathrm{CD} 3 \mathrm{e}^{+} \mathrm{CD} 4^{+}$and $\mathrm{CD} 3 \mathrm{e}^{+} \mathrm{CD} 8^{+}$cells were significantly promoted in all vaccinated mice compared to those in the blank and control group. This observation indicated that animals immunized with TgSDRO-pVAX1/CS and TgSDRO-pVAX1/PLGA nanospheres could elicit higher levels of $\mathrm{CD}^{+}$and $\mathrm{CD}^{+} \mathrm{T}$ lymphocytes, which may contribute to the humoral and cellular immunity against acute toxoplasmosis. The ability of two types of nanospheres to enhance the proportions of $\mathrm{CD}^{+}$and $\mathrm{CD}^{+} \mathrm{T}$ lymphocytes was similar to that noted in the previous studies $(17,31,106)$.

The parasite burden of vaccinated animals against T. gondii challenge is regarded as the most direct indicator to assess a vaccine. Therefore, an acute infection model was established to analyze the $T$. gondii burden in cardiac muscles. In comparison with the blank and control group, animals from TgSDROpVAX1, TgSDRO-pVAX1/CS, and TgSDRO-pVAX1/PLGA groups presented an obvious inhibition in T. gondii infections, demonstrating the immune protection, which was similar to previous studies employing different DNA vaccines (17, 107, 108). In addition, our results also indicated that TgSDROpVAX1/PLGA nanospheres were more efficient than TgSDROpVAX1/CS nanospheres in resisting the replications of T. gondii. Thus, TgSDRO-pVAX1/PLGA nanospheres may have more potential for the prevention of acute toxoplasmosis.

\section{CONCLUSION}

In summary, this study suggests that immunizations with TgSDRO-pVAX1/CS and TgSDRO-pVAX1/PLGA nanospheres could generate immune protection against acute $T$. gondii infection with a significantly lower parasite burden in animals. The regulated antibodies and cytokine secretions and the flow cytometry results suggest that TgSDRO-pVAX1/CS and TgSDRO-pVAX1/PLGA nanospheres could trigger Th1/Th2 cellular and humoral immunity in mice. As the potent delivery system, chitosan and PLGA can enhance cellular immunity by inducing Th1 biased immune responses. Furthermore, as the promising DNA vaccines, TgSDRO-pVAX1/CS and TgSDROpVAX1/PLGA nanospheres can generate similar immune protection and are substitutes for each other. However, the immune mechanisms of TgSDRO-pVAX1/CS and TgSDROpVAX1/PLGA nanospheres are complicated and required more studies. The subsequent studies on this promising DNA vaccine should improve the loading capacity to enhance the immune protection and shed light on its applicable conditions to other hosts and its protectivity against chronic toxoplasmosis.

\section{DATA AVAILABILITY STATEMENT}

The original contributions presented in the study are included in the article/supplementary material. Further inquiries can be directed to the corresponding author.

\section{ETHICS STATEMENT}

The animal study was reviewed and approved by the animal ethics committee of the responsible authority from the College of Veterinary Medicine, Nanjing Agricultural University, China.

\section{AUTHOR CONTRIBUTIONS}

ZY: Investigation, data curation, writing-original draft, formal analysis, and methodology. WC: Data curation, investigation, and formal analysis. XG: Investigation, methodology, and writing-review and editing. MA: Data curation, investigation, and writing-review and editing. JLi: Data curation, methodology, and funding acquisition. JLu: Methodology and funding acquisition. RY: Methodology, supervision, and project administration. LX: Methodology, funding acquisition, and project administration. XS: Methodology, project administration, and writing-review and editing. XL: Conceptualization, data curation, funding acquisition, methodology, supervision, writing — original draft, and writing — review and editing. All authors contributed to the article and approved the submitted version. 


\section{FUNDING}

This research was supported by Key Scientific and Technological Project of XPCC (2020AB025), College Students' innovation and entrepreneurship training program (202010307099), and State Key Laboratory of Veterinary Etiological Biology, Lanzhou Veterinary Research Institute, Chinese Academy of Agricultural Sciences.

\section{REFERENCES}

1. Dubey JP, Hotea I, Olariu TR, Jones JL, Darabus G. Epidemiological Review of Toxoplasmosis in Humans and Animals in Romania. Parasitology (2014) 141(3):311-25. doi: 10.1017/S0031182013001509

2. Montoya JG, Liesenfeld O. Toxoplasmosis. Lancet (2004) 363(9425):196576. doi: 10.1016/s0140-6736(04)16412-x

3. Weiss LM, Dubey JP. Toxoplasmosis: A History of Clinical Observations. Int J Parasitol (2009) 39(8):895-901. doi: 10.1016/j.ijpara.2009.02.004

4. Sroka J, Bilska-Zajac E, Wojcik-Fatla A, Zajac V, Dutkiewicz J, Karamon J, et al. Detection and Molecular Characteristics of Toxoplasma Gondii DNA in Retail Raw Meat Products in Poland. Foodborne Pathog Dis (2019) 16 (3):195-204. doi: 10.1089/fpd.2018.2537

5. Marques CS, Sousa S, Castro A, da Costa JMC. Detection of Toxoplasma Gondii Oocysts in Fresh Vegetables and Berry Fruits. Parasit Vectors (2020) 13(1):180. doi: 10.1186/s13071-020-04040-2

6. Hernandez-Cortazar IB, Acosta-Viana KY, Guzman-Marin E, OrtegaPacheco A, Segura-Correa JC, Jimenez-Coello M. Presence of Toxoplasma Gondii in Drinking Water From an Endemic Region in Southern Mexico. Foodborne Pathog Dis (2017) 14(5):288-92. doi: 10.1089/fpd.2016.2224

7. Aguirre AA, Longcore T, Barbieri M, Dabritz H, Hill D, Klein PN, et al. The One Health Approach to Toxoplasmosis: Epidemiology, Control, and Prevention Strategies. Ecohealth (2019) 16(2):378-90. doi: 10.1007/ s10393-019-01405-7

8. Dittmar AJ, Drozda AA, Blader IJ. Drug Repurposing Screening Identifies Novel Compounds That Effectively Inhibit Toxoplasma Gondii Growth. Msphere (2016) 1(2):e00042-15. doi: 10.1128/mSphere.00042-15

9. Lyons RE, McLeod R, Roberts CW. Toxoplasma Gondii TachyzoiteBradyzoite Interconversion. Trends Parasitol (2002) 18(5):198-201. doi: 10.1016/S1471-4922(02)02248-1

10. Rajapakse S, Weeratunga P, Rodrigo C, de Silva NL, Fernando SD. Prophylaxis of Human Toxoplasmosis: A Systematic Review. Pathog Glob Health (2017) 111(7):333-42. doi: 10.1080/20477724.2017.1370528

11. group Ss, Thiebaut R, Leproust S, Chene G, Gilbert R. Effectiveness of Prenatal Treatment for Congenital Toxoplasmosis: A Meta-Analysis of Individual Patients' Data. Lancet (2007) 369(9556):115-22. doi: 10.1016/ S0140-6736(07)60072-5

12. Buxton D, Innes EA. A Commercial Vaccine for Ovine Toxoplasmosis. Parasitology (1995) 110 Suppl:S11-6. doi: 10.1017/s003118200000144x

13. AMCSF. Risk Profile in Relation to Toxoplasma in the Food Chain (2012). Available at: http://www.innocua.net/web/download-310/acmsfrtaxopasm.pdf.

14. Rezaei F, Sarvi S, Sharif M, Hejazi SH, Pagheh AS, Aghayan SA, et al. A Systematic Review of Toxoplasma Gondii Antigens to Find the Best Vaccine Candidates for Immunization. Microb Pathog (2019) 126:172-84. doi: 10.1016/j.micpath.2018.11.003

15. Hajissa K, Zakaria R, Suppian R, Mohamed Z. Epitope-Based Vaccine as a Universal Vaccination Strategy Against Toxoplasma Gondii Infection: A MiniReview. J Adv Vet Anim Res (2019) 6(2):174-82. doi: 10.5455/javar.2019.f329

16. Zheng B, Lou D, Ding J, Zhuo X, Ding H, Kong Q, et al. GRA24-Based DNA Vaccine Prolongs Survival in Mice Challenged With a Virulent Toxoplasma Gondii Strain. Front Immunol (2019) 10:418. doi: 10.3389/fimmu.2019.00418

17. Sun H, Li J, Xiao T, Huang XD, Wang LJ, Huang BC, et al. Protective Immunity Induced by a DNA Vaccine Cocktail Expressing TgSAG1, TgROP2, and the Genetic Adjuvant HBsAg Against Toxoplasma Gondii Infection. Microb Pathog (2020) 147:104441. doi: 10.1016/j.micpath.2020.104441

18. Lu G, Zhou J, Zhao YH, Wang L. DNA Vaccine ROP29 From Toxoplasma Gondii Containing R848 Enhances Protective Immunity in Mice. Parasite Immunol (2018) 40(10):e12578. doi: 10.1111/pim.12578

\section{ACKNOWLEDGMENTS}

We acknowledge Yanli Yu in Ningxia University, Yinchuan, China for her help on statistical analysis. For the technical assistance, we greatly thank HaiFeng Sun in MOA Key Laboratory of Animal Bacteriology, Nanjing Agricultural University, Nanjing, China.

19. Tao Q, Fang R, Zhang W, Wang Y, Cheng J, Li Y, et al. Protective Immunity Induced by a DNA Vaccine-Encoding Toxoplasma Gondii Microneme Protein 11 Against Acute Toxoplasmosis in BALB/c Mice. Parasitol Res (2013) 112(8):2871-7. doi: 10.1007/s00436-013-3458-4

20. Zhang NZ, Wang M, Xu Y, Petersen E, Zhu XQ. Recent Advances in Developing Vaccines Against Toxoplasma Gondii: An Update. Expert Rev Vaccines (2015) 14(12):1609-21. doi: 10.1586/14760584.2015.1098539

21. Montazeri M, Sharif M, Sarvi S, Mehrzadi S, Ahmadpour E. Daryani A. A Systematic Review of In Vitro and In Vivo Activities of Anti-Toxoplasma Drugs and Compounds (2006-2016). Front Microbiol (2017) 8:25. doi: $10.3389 /$ fmicb. 2017.00025

22. Li Y, Zhou H. Moving Towards Improved Vaccines for Toxoplasma Gondii. Expert Opin Biol Ther (2018) 18(3):273-80. doi: 10.1080/14712598.2018. 1413086

23. Beck KR, Kaserer T, Schuster D, Odermatt A. Virtual Screening Applications in Short-Chain Dehydrogenase/Reductase Research. J Steroid Biochem Mol Biol (2017) 171:157-77. doi: 10.1016/j.jsbmb.2017.03.008

24. Persson B, Kallberg Y, Bray JE, Bruford E, Dellaporta SL, Favia AD, et al. (Short-Chain Dehydrogenase/Reductase and Related Enzymes) Nomenclature Initiative. Chem Biol Interact (2009) 178(1-3):94-8. doi: 10.1016/j.cbi.2008.10.040

25. Kallberg Y, Oppermann U, Jornvall H, Persson B. Short-Chain Dehydrogenases/Reductases (SDRs). Eur J Biochem (2002) 269(18):440917. doi: 10.1046/j.1432-1033.2002.03130.x

26. Persson B, Kallberg Y, Oppermann U, Jornvall H. Coenzyme-Based Functional Assignments of Short-Chain Dehydrogenases/Reductases (SDRs). Chem Biol Interact (2003) 143-144:271-8. doi: 10.1016/s0009-2797(02)00223-5

27. Matsumoto K, Tanaka Y, Watanabe T, Motohashi R, Ikeda K, Tobitani K, et al. Directed Evolution and Structural Analysis of NADPH-Dependent Acetoacetyl Coenzyme A (Acetoacetyl-CoA) Reductase From Ralstonia Eutropha Reveals Two Mutations Responsible for Enhanced Kinetics. Appl Environ Microbiol (2013) 79(19):6134-9. doi: 10.1128/AEM.01768-13

28. Dubois DJ, Soldati-Favre D. Biogenesis and Secretion of Micronemes in Toxoplasma Gondii. Cell Microbiol (2019) 21(5):e13018. doi: 10.1111/ cmi.13018

29. Waller RF, Keeling PJ, Donald RG, Striepen B, Handman E, Lang-Unnasch $\mathrm{N}$, et al. Nuclear-Encoded Proteins Target to the Plastid in Toxoplasma Gondii and Plasmodium Falciparum. Proc Natl Acad Sci USA (1998) 95 (21):12352-7. doi: 10.1073/pnas.95.21.12352

30. Tomova C, Humbel BM, Geerts WJ, Entzeroth R, Holthuis JC, Verkleij AJ. Membrane Contact Sites Between Apicoplast and ER in Toxoplasma Gondii Revealed by Electron Tomography. Traffic (2009) 10(10):1471-80. doi: 10.1111/j.1600-0854.2009.00954.x

31. Zheng B, Ding J, Lou D, Tong Q, Zhuo X, Ding H, et al. The VirulenceRelated MYR1 Protein of Toxoplasma Gondii as a Novel DNA Vaccine Against Toxoplasmosis in Mice. Front Microbiol (2019) 10:734. doi: 10.3389/ fmicb.2019.00734

32. Li L, Petrovsky N. Molecular Mechanisms for Enhanced DNA Vaccine Immunogenicity. Expert Rev Vaccines (2016) 15(3):313-29. doi: 10.1586/ 14760584.2016.1124762

33. Saade F, Petrovsky N. Technologies for Enhanced Efficacy of DNA Vaccines. Expert Rev Vaccines (2012) 11(2):189-209. doi: 10.1586/erv.11.188

34. Lim M, Badruddoza AZM, Firdous J, Azad M, Mannan A, Al-Hilal TA, et al. Engineered Nanodelivery Systems to Improve DNA Vaccine Technologies. Pharmaceutics (2020) 12(1):30-58. doi: 10.3390/pharmaceutics 12010030

35. Chereddy KK, Vandermeulen G, Preat V. PLGA Based Drug Delivery Systems: Promising Carriers for Wound Healing Activity. Wound Repair Regener (2016) 24(2):223-36. doi: 10.1111/wrr.12404 
36. Wedmore I, McManus JG, Pusateri AE, Holcomb JB. A Special Report on the Chitosan-Based Hemostatic Dressing: Experience in Current Combat Operations. J Trauma (2006) 60(3):655-8. doi: 10.1097/01.ta.0000199392. 91772.44

37. Illum L. Chitosan and its Use as a Pharmaceutical Excipient. Pharm Res (1998) 15(9):1326-31. doi: 10.1023/a:1011929016601

38. Kumar MNVR. A Review of Chitin and Chitosan Applications. React Funct Polym (2000) 46(1):1-27. doi: 10.1016/S1381-5148(00)00038-9

39. Buschmann MD, Merzouki A, Lavertu M, Thibault M, Jean M, Darras V. Chitosans for Delivery of Nucleic Acids. Adv Drug Deliver Rev (2013) 65 (9):1234-70. doi: 10.1016/j.addr.2013.07.005

40. Wang WQ, Meng QY, Li Q, Liu JB, Zhou M, Jin Z, et al. Chitosan Derivatives and Their Application in Biomedicine. Int J Mol Sci (2020) 21 (2):487-512. doi: 10.3390/ijms 21020487

41. Wang S, Zhao GW, Wang W, Xie Q, Zhang M, Yuan C, et al. Pathogenicity of Two Toxoplasma Gondii Strains in Chickens of Different Ages Infected via Intraperitoneal Injection. Avian Pathol (2014) 43(1):91-5. doi: 10.1080/ 03079457.2013.874007

42. Salari F, Varasteh AR, Vahedi F, Hashemi M, Sankian M. Down-Regulation of Th2 Immune Responses by Sublingual Administration of Poly (Lactic-CoGlycolic) Acid (PLGA)-Encapsulated Allergen in BALB/c Mice. Int Immunopharmacol (2015) 29(2):672-8. doi: 10.1016/j.intimp.2015.09.011

43. Fan W, Yan W, Xu Z, Ni H. Formation Mechanism of Monodisperse, Low Molecular Weight Chitosan Nanoparticles by Ionic Gelation Technique. Colloids Surf B Biointerf (2012) 90:21-7. doi: 10.1016/j.colsurfb.2011.09.042

44. Skop NB, Calderon F, Levison SW, Gandhi CD, Cho CH. Heparin Crosslinked Chitosan Microspheres for the Delivery of Neural Stem Cells and Growth Factors for Central Nervous System Repair. Acta Biomater (2013) 9(6):6834-43. doi: 10.1016/j.actbio.2013.02.043

45. Zhang M, Yang Z, Wang S, Tao L, Xu L, Yan R, et al. Detection of Toxoplasma Gondii in Shellfish and Fish in Parts of China. Vet Parasitol (2014) 200(1-2):85-9. doi: 10.1016/j.vetpar.2013.10.022

46. Homan WL, Vercammen M, De Braekeleer J, Verschueren H. Identification of a 200- to 300-Fold Repetitive 529 Bp DNA Fragment in Toxoplasma Gondii, and Its Use for Diagnostic and Quantitative PCR. Int J Parasitol (2000) 30(1):69-75. doi: 10.1016/s0020-7519(99)00170-8

47. Wang JL, Elsheikha HM, Zhu WN, Chen K, Li TT, Yue DM, et al. Immunization With Toxoplasma Gondii GRA17 Deletion Mutant Induces Partial Protection and Survival in Challenged Mice. Front Immunol (2017) 8:730. doi: 10.3389/fimmu.2017.00730

48. Wang S, Fang Z, Huang X, Luo X, Fang Z, Gong N, et al. The Soluble Tachyzoite Antigen of Toxoplasma Gondii Has a Protective Effect on Mouse Allografts. Transpl P (2013) 45(2):677-83. doi: 10.1016/j.transproceed.2012.02.036

49. Tang XM, Yin GW, Qin M, Tao GR, Suo JX, Liu XY, et al. Transgenic Eimeria Tenella as a Vaccine Vehicle: Expressing TgSAG1 Elicits Protective Immunity Against Toxoplasma Gondii Infections in Chickens and Mice. Sci Rep-Uk (2016) 6:29379-87. doi: 10.1038/srep29379

50. O'Hagan DT, Singh M, Ulmer JB. Microparticle-Based Technologies for Vaccines. Methods (2006) 40(1):10-9. doi: 10.1016/j.ymeth.2006.05.017

51. Tacken PJ, Zeelenberg IS, Cruz LJ, van Hout-Kuijer MA, van de Glind G, Fokkink RG, et al. Targeted Delivery of TLR Ligands to Human and Mouse Dendritic Cells Strongly Enhances Adjuvanticity. Blood (2011) 118 (26):6836-44. doi: 10.1182/blood-2011-07-367615

52. Hamdy S, Haddadi A, Hung RW, Lavasanifar A. Targeting Dendritic Cells With Nano-Particulate PLGA Cancer Vaccine Formulations. Adv Drug Delivery Rev (2011) 63(10-11):943-55. doi: 10.1016/j.addr.2011.05.021

53. De Temmerman ML, Rejman J, Demeester J, Irvine DJ, Gander B. De Smedt SC. Particulate Vaccines: On the Quest for Optimal Delivery and Immune Response. Drug Discovery Today (2011) 16(13-14):569-82. doi: 10.1016/ j.drudis.2011.04.006

54. Abd El Hady WE, Mohamed EA, Soliman OAE, El-Sabbagh HM. In Vitro-In Vivo Evaluation of Chitosan-PLGA Nanoparticles for Potentiated Gastric Retention and Anti-Ulcer Activity of Diosmin. Int J Nanomed (2019) 14:7191-213. doi: 10.2147/IJN.S213836

55. Silva AL, Soema PC, Slutter B, Ossendorp F, Jiskoot W. PLGA Particulate Delivery Systems for Subunit Vaccines: Linking Particle Properties to Immunogenicity. Hum Vaccin Immunother (2016) 12(4):1056-69. doi: $10.1080 / 21645515.2015 .1117714$
56. Jreyssaty C, Shi Q, Wang H, Qiu X, Winnik FM, Zhang X, et al. Efficient Nonviral Gene Therapy Using Folate-Targeted Chitosan-DNA Nanoparticles In Vitro. ISRN Pharm (2012) 2012:369270. doi: 10.5402/ 2012/369270

57. Islam MA, Firdous J, Choi YJ, Yun CH, Cho CS. Design and Application of Chitosan Microspheres as Oral and Nasal Vaccine Carriers: An Updated Review. Int J Nanomed (2012) 7:6077-93. doi: 10.2147/ijn.S38330

58. Carroll EC, Jin L, Mori A, Munoz-Wolf N, Oleszycka E, Moran HBT, et al. The Vaccine Adjuvant Chitosan Promotes Cellular Immunity via DNA Sensor cGAS-STING-Dependent Induction of Type I Interferons. Immunity (2016) 44(3):597-608. doi: 10.1016/j.immuni.2016.02.004

59. Bowman K, Leong KW. Chitosan Nanoparticles for Oral Drug and Gene Delivery. Int J Nanomed (2006) 1(2):117-28. doi: 10.2147/nano.2006.1.2.117

60. Zheng FR, Liu HZ, Sun XQ, Zhang YQ, Zhang BY, Teng ZJ, et al. Development of Oral DNA Vaccine Based on Chitosan Nanoparticles for the Immunization Against Reddish Body Iridovirus in Turbots (Scophthalmus Maximus). Aquaculture (2016) 452:263-71. doi: 10.1016/ j.aquaculture.2015.11.013

61. Leya T, Ahmad I, Sharma R, Tripathi G, Kurcheti PP, Rajendran KV, et al. Bicistronic DNA Vaccine Macromolecule Complexed With Poly Lactic-CoGlycolic Acid-Chitosan Nanoparticles Enhanced the Mucosal Immunity of Labeo Rohita Against Edwardsiella Tarda Infection. Int J Biol Macromol (2020) 156:928-37. doi: 10.1016/j.ijbiomac.2020.04.048

62. Cebrian V, Martin-Saavedra F, Yague C, Arruebo M, Santamaria J, Vilaboa N. Size-Dependent Transfection Efficiency of PEI-Coated Gold Nanoparticles. Acta Biomater (2011) 7(10):3645-55. doi: 10.1016/ j.actbio.2011.06.018

63. Prabha S, Arya G, Chandra R, Ahmed B, Nimesh S. Effect of Size on Biological Properties of Nanoparticles Employed in Gene Delivery. Artif Cells Nanomed Biotechnol (2016) 44(1):83-91. doi: 10.3109/21691401. 2014.913054

64. Gratton SE, Ropp PA, Pohlhaus PD, Luft JC, Madden VJ, Napier ME, et al. The Effect of Particle Design on Cellular Internalization Pathways. Proc Natl Acad Sci USA (2008) 105(33):11613-8. doi: 10.1073/pnas.0801763105

65. Wang W. Lyophilization and Development of Solid Protein Pharmaceuticals. Int J Pharm (2000) 203(1-2):1-60. doi: 10.1016/s0378-5173(00)00423-3

66. Fonte P, Araújo F, Seabra V, Reis S, van de Weert M, Sarmento B. CoEncapsulation of Lyoprotectants Improves the Stability of Protein-Loaded PLGA Nanoparticles Upon Lyophilization. Int J Pharm (2015) 496(2):85062. doi: 10.1016/j.ijpharm.2015.10.032

67. Ramamoorth M, Narvekar A. Non Viral Vectors in Gene Therapy- an Overview. J Clin Diagn Res (2015) 9(1):GE01-6. doi: 10.7860/JCDR/2015/ 10443.5394

68. Koppolu BP, Smith SG, Ravindranathan S, Jayanthi S, Suresh Kumar TK, Zaharoff DA. Controlling Chitosan-Based Encapsulation for Protein and Vaccine Delivery. Biomaterials (2014) 35(14):4382-9. doi: 10.1016/ j.biomaterials.2014.01.078

69. Schlosser PM, Bale AS, Gibbons CF, Wilkins A, Cooper GS. Human Health Effects of Dichloromethane: Key Findings and Scientific Issues. Environ Health Persp (2015) 123(2):114-9. doi: 10.1289/ehp.1308030

70. Opsteegh M, Langelaar M, Sprong H, den Hartog L, De Craeye S, Bokken G, et al. Direct Detection and Genotyping of Toxoplasma Gondii in Meat Samples Using Magnetic Capture and PCR. Int J Food Microbiol (2010) 139 (3):193-201. doi: 10.1016/j.ijfoodmicro.2010.02.027

71. Gisbert Algaba I, Verhaegen B, Jennes M, Rahman M, Coucke W, Cox E, et al. Pork as a Source of Transmission of Toxoplasma Gondii to Humans: A Parasite Burden Study in Pig Tissues After Infection With Different Strains of Toxoplasma Gondii as a Function of Time and Different Parasite Stages. Int J Parasitol (2018) 48(7):555-60. doi: 10.1016/j.ijpara.2017.12.009

72. Juránková J, Basso W, Neumayerová H, Baláž V, Jánová E, Sidler X, et al. Brain is the Predilection Site of Toxoplasma Gondii in Experimentally Inoculated Pigs as Revealed by Magnetic Capture and Real-Time PCR. Food Microbiol (2014) 38:167-70. doi: 10.1016/j.fm.2013.08.011

73. Yoshida N, Frickel EM, Mostowy S. Macrophage-Microbe Interactions: Lessons From the Zebrafish Model. Front Immunol (2017) 8:1703. doi: 10.3389/fimmu.2017.01703

74. Lakhrif Z, Moreau A, Herault B, Di-Tommaso A, Juste M, Moire N, et al. Targeted Delivery of Toxoplasma Gondii Antigens to Dendritic Cells Promote 
Immunogenicity and Protective Efficiency Against Toxoplasmosis. Front Immunol (2018) 9:317. doi: 10.3389/fimmu.2018.00317

75. Germann T, Bongartz M, Dlugonska H, Hess H, Schmitt E, Kolbe L, et al. Interleukin-12 Profoundly Up-Regulates the Synthesis of Antigen-Specific Complement-Fixing IgG2a, IgG2b and IgG3 Antibody Subclasses In Vivo. Eur J Immunol (1995) 25(3):823-9. doi: 10.1002/eji.1830250329

76. Yarovinsky F. Innate Immunity to Toxoplasma Gondii Infection. Nat Rev Immunol (2014) 14(2):109-21. doi: 10.1038/nri3598

77. Sasai M, Pradipta A, Yamamoto M. Host Immune Responses to Toxoplasma Gondii. Int Immunol (2018) 30(3):113-9. doi: 10.1093/intimm/dxy004

78. Pifer R, Yarovinsky F. Innate Responses to Toxoplasma Gondii in Mice and Humans. Trends Parasitol (2011) 27(9):388-93. doi: 10.1016/j.pt.2011.03.009

79. Innes EA, Bartley PM, Buxton D, Katzer F. Ovine Toxoplasmosis. Parasitology (2009) 136(14):1887-94. doi: 10.1017/s0031182009991636

80. Sonaimuthu P, Ching XT, Fong MY, Kalyanasundaram R, Lau YL. Induction of Protective Immunity Against Toxoplasmosis in BALB/c Mice Vaccinated With Toxoplasma Gondii Rhoptry-1. Front Microbiol (2016) 7:808. doi: 10.3389/fmicb.2016.00808

81. Ching XT, Fong MY, Lau YL. Evaluation of Immunoprotection Conferred by the Subunit Vaccines of GRA2 and GRA5 Against Acute Toxoplasmosis in BALB/c Mice. Front Microbiol (2016) 7:609. doi: 10.3389/fmicb.2016.00609

82. Bessieres MH, Swierczynski B, Cassaing S, Miedouge M, Olle P, Seguela JP, et al. Role of IFN-Gamma, TNF-Alpha, IL4 and IL10 in the Regulation of Experimental Toxoplasma Gondii Infection. J Eukaryot Microbiol (1997) 44 (6):87s. doi: 10.1111/j.1550-7408.1997.tb05800.x

83. Gigley JP, Fox BA, Bzik DJ. Cell-Mediated Immunity to Toxoplasma Gondii Develops Primarily by Local Th1 Host Immune Responses in the Absence of Parasite Replication. J Immunol (2009) 182(2):1069-78. doi: 10.4049/ jimmunol.182.2.1069

84. Tan F, Hu X, Luo FJ, Pan CW, Chen XG. Induction of Protective Th1 Immune Responses in Mice by Vaccination With Recombinant Toxoplasma Gondii Nucleoside Triphosphate Hydrolase-II. Vaccine (2011) 29(15):27428. doi: 10.1016/j.vaccine.2011.01.089

85. Song X, Gao H, Qian Y. Th17 Differentiation and Their Pro-Inflammation Function. Adv Exp Med Biol (2014) 841:99-151. doi: 10.1007/978-94-0179487-9_5

86. Kelly MN, Kolls JK, Happel K, Schwartzman JD, Schwarzenberger P, Combe C, et al. Interleukin-17/Interleukin-17 Receptor-Mediated Signaling is Important for Generation of an Optimal Polymorphonuclear Response Against Toxoplasma Gondii Infection. Infect Immun (2005) 73(1):617-21. doi: 10.1128/iai.73.1.617-621.2005

87. Guiton R, Vasseur V, Charron S, Arias MT, Van Langendonck N, BuzoniGatel D, et al. Interleukin 17 Receptor Signaling is Deleterious During Toxoplasma Gondii Infection in Susceptible BL6 Mice. J Infect Dis (2010) 202(3):427-35. doi: 10.1086/653738

88. Howard CJ, Charleston B, Stephens SA, Sopp P, Hope JC. The Role of Dendritic Cells in Shaping the Immune Response. Anim Health Res Rev (2004) 5(2):191-5. doi: 10.1079/ahr200468

89. Mellman I. Dendritic Cells: Master Regulators of the Immune Response. Cancer Immunol Res (2013) 1(3):145-9. doi: 10.1158/2326-6066.CIR-13-0102

90. Walseng E, Furuta K, Goldszmid RS, Weih KA, Sher A, Roche PA. Dendritic Cell Activation Prevents MHC Class II Ubiquitination and Promotes MHC Class II Survival Regardless of the Activation Stimulus. J Biol Chem (2010) 285(53):41749-54. doi: 10.1074/jbc.M110.157586

91. Banchereau J, Steinman RM. Dendritic Cells and the Control of Immunity. Nature (1998) 392(6673):245-52. doi: 10.1038/32588

92. Grosche L, Knippertz I, Konig C, Royzman D, Wild AB, Zinser E, et al. The CD83 Molecule - An Important Immune Checkpoint. Front Immunol (2020) 11:721. doi: 10.3389/fimmu.2020.00721

93. Banchereau J, Briere F, Caux C, Davoust J, Lebecque S, Liu YJ, et al. Immunobiology of Dendritic Cells. Annu Rev Immunol (2000) 18:767811. doi: 10.1146/annurev.immunol.18.1.767

94. Reis e Sousa C. Activation of Dendritic Cells: Translating Innate Into Adaptive Immunity. Curr Opin Immunol (2004) 16(1):21-5. doi: 10.1016/ j.coi.2003.11.007

95. Trombetta ES, Mellman I. Cell Biology of Antigen Processing In Vitro and In Vivo. Annu Rev Immunol (2005) 23:975-1028. doi: 10.1146/ annurev.immunol.22.012703.104538
96. Fredriksen AB, Sandlie I, Bogen B. DNA Vaccines Increase Immunogenicity of Idiotypic Tumor Antigen by Targeting Novel Fusion Proteins to AntigenPresenting Cells. Mol Ther (2006) 13(4):776-85. doi: 10.1016/j.ymthe.2005.10.019

97. Grodeland G, Mjaaland S, Roux KH, Fredriksen AB, Bogen B. DNA Vaccine That Targets Hemagglutinin to MHC Class II Molecules Rapidly Induces Antibody-Mediated Protection Against Influenza. J Immunol (2013) 191 (6):3221-31. doi: 10.4049/jimmunol.1300504

98. Lyons RE, Anthony JP, Ferguson DJP, Byrne N, Alexander J, Roberts F, et al. Immunological Studies of Chronic Ocular Toxoplasmosis: Up-Regulation of Major Histocompatibility Complex Class I and Transforming Growth Factor Beta and a Protective Role for Interleukin-6. Infect Immun (2001) 69 (4):2589-95. doi: 10.1128/Iai.69.4.2589-2595.2001

99. Zhou F. Molecular Mechanisms of IFN-Gamma to Up-Regulate MHC Class I Antigen Processing and Presentation. Int Rev Immunol (2009) 28(34):239-60. doi: 10.1080/08830180902978120

100. Martini M, Testi MG, Pasetto M, Picchio MC, Innamorati G, Mazzocco M, et al. IFN-Gamma-Mediated Upmodulation of MHC Class I Expression Activates Tumor-Specific Immune Response in a Mouse Model of Prostate Cancer. Vaccine (2010) 28(20):3548-57. doi: 10.1016/j.vaccine.2010.03.007

101. Luo L, Qin T, Huang Y, Zheng S, Bo R, Liu Z, et al. Exploring the Immunopotentiation of Chinese Yam Polysaccharide Poly(Lactic-Co-Glycolic Acid) Nanoparticles in an Ovalbumin Vaccine Formulation In Vivo. Drug Delivery (2017) 24(1):1099-111. doi: 10.1080/10717544.2017.1359861

102. Dupont CD, Christian DA, Selleck EM, Pepper M, Leney-Greene M, Harms Pritchard G, et al. Parasite Fate and Involvement of Infected Cells in the Induction of $\mathrm{CD}^{+}$and $\mathrm{CD} 8^{+} \mathrm{T}$ Cell Responses to Toxoplasma Gondii. PloS Pathog (2014) 10(4):e1004047. doi: 10.1371/journal.ppat.1004047

103. Kemball CC, Pack CD, Guay HM, Li ZN, Steinhauer DA, Szomolanyi-Tsuda E, et al. The Antiviral CD8 ${ }^{+} \mathrm{T}$ Cell Response is Differentially Dependent on $\mathrm{CD}^{+} \mathrm{T}$ Cell Help Over the Course of Persistent Infection. J Immunol (2007) 179(2):1113-21. doi: 10.4049/jimmunol.179.2.1113

104. Dupont CD, Christian DA, Hunter CA. Immune Response and Immunopathology During Toxoplasmosis. Semin Immunopathol (2012) 34(6):793-813. doi: 10.1007/s00281-012-0339-3

105. Laidlaw BJ, Craft JE, Kaech SM. The Multifaceted Role of CD4 ${ }^{+} \mathrm{T}$ Cells in $\mathrm{CD}^{+}{ }^{+}$T Cell Memory. Nat Rev Immunol (2016) 16(2):102-11. doi: 10.1038/ nri.2015.10

106. Liu Y, Cao A, Li Y, Li X, Cong H, He S, et al. Immunization With a DNA Vaccine Encoding Toxoplasma Gondii Superoxide Dismutase (TgSOD) Induces Partial Immune Protection Against Acute Toxoplasmosis in BALB/c Mice. BMC Infect Dis (2017) 17(1):403. doi: 10.1186/s12879-0172507-5

107. Zhao G, Zhou A, Lu G, Meng M, Sun M, Bai Y, et al. Identification and Characterization of Toxoplasma Gondii Aspartic Protease 1 as a Novel Vaccine Candidate Against Toxoplasmosis. Parasit Vectors (2013) 6:175. doi: 10.1186/1756-3305-6-175

108. Hassan IA, Wang S, Xu L, Yan R, Song X, Li X. DNA Vaccination With a Gene Encoding Toxoplasma Gondii Deoxyribose Phosphate Aldolase (TgDPA) Induces Partial Protective Immunity Against Lethal Challenge in Mice. Parasit Vectors (2014) 7:431. doi: 10.1186/1756-3305-7-431

Conflict of Interest: The authors declare that the research was conducted in the absence of any commercial or financial relationships that could be construed as a potential conflict of interest.

Publisher's Note: All claims expressed in this article are solely those of the authors and do not necessarily represent those of their affiliated organizations, or those of the publisher, the editors and the reviewers. Any product that may be evaluated in this article, or claim that may be made by its manufacturer, is not guaranteed or endorsed by the publisher.

Copyright $\odot 2021 \mathrm{Yu}, \mathrm{Cao}$, Gao, Aleem, Liu, Luo, Yan, Xu, Song and Li. This is an open-access article distributed under the terms of the Creative Commons Attribution License (CC BY). The use, distribution or reproduction in other forums is permitted, provided the original author(s) and the copyright owner(s) are credited and that the original publication in this journal is cited, in accordance with accepted academic practice. No use, distribution or reproduction is permitted which does not comply with these terms. 